https://helda.helsinki.fi

\title{
Laser scanning applications in fluvial studies
}

\section{Hohenthal, Johanna}

2011

Hohenthal , J , Alho , P , Hyyppä , J \& Hyyppä , H 2011 , ' Laser scanning applications in

fluvial studies ' , Progress in Physical Geography , vol. 35 , no. 6 , pp. 782-809 . https://doi.org/10.1177/0309133311

http://hdl.handle.net/10138/29811

https://doi.org/10.1177/0309133311414605

publishedVersion

Downloaded from Helda, University of Helsinki institutional repository.

This is an electronic reprint of the original article.

This reprint may differ from the original in pagination and typographic detail.

Please cite the original version. 
Progress in Physical Geography 35(6) 782-809

\title{
Laser scanning applications in fluvial studies
}

\section{Johanna Hohenthal}

University of Helsinki, Finland

\section{Petteri Alho}

University of Turku, Finland; Aalto University, Finland

\section{Juha Hyyppä}

Finnish Geodetic Institute, Finland

\section{Hannu Hyyppä}

Aalto University, Finland

\begin{abstract}
During recent decades, the use of high-resolution light detection and ranging altimetry (LiDAR) data in fluvial studies has rapidly increased. Airborne laser scanning (ALS) can be used to extensively map riverine topography. Although airborne blue/green LiDAR can also be utilized for the mapping of river bathymetry, the accuracy levels achieved are not as good as those of terrain elevation measurements. Moreover, airborne bathymetric LiDAR is not yet suitable for mapping shallow water areas. More detailed topographical data may be obtained by fixed-position terrestrial laser scanning (TLS) or mobile terrestrial laser scanning (MLS). One of the newest applications of MLS approaches involves a boat/cart-based mobile mapping system (BoMMS/CartMMS). This set-up includes laser scanning and imaging from a boat moving along a river course and may be used to expand the spatial extent of terrestrial scanning. Detailed digital terrain models (DTMs) derived from LiDAR data can be used to improve the recognition of fluvial landforms, the geometric data of hydraulic modelling, and the estimation of flood inundation extents and fluvial processes.
\end{abstract}

\section{Keywords}

digital terrain model, fluvial studies, laser scanning, LiDAR, mobile mapping, river

\section{Introduction}

In a fluvial environment, the erosion, transport and accumulation of sediments by flowing water greatly affect the geomorphology of both the river channel and surrounding floodplain. From the mid- to late 20th century, fluvial studies concentrated mainly on process analysis by measuring flows and sediment transport rates (Rumsby et al., 2008). However, this allowed the detection of the changes in riverine topography in only one or two dimensions (cross-section, planform, long profile). Data collection was conducted either locally and intensively or was spatially extensive but sparse, thus giving a discontinuous picture of the river reach under investigation (Marcus and Fonstand, 2008).

\footnotetext{
Corresponding author:

Johanna Hohenthal, Department of Geosciences and Geography, PO Box 64, Gustaf Hällströminkatu 2, $\mathrm{FI}-000 \mathrm{I} 4$ University of Helsinki, Finland

Email: johanna.hohenthal@helsinki.fi
} 
Recently, the growing understanding of the interaction between surface morphology and geomorphological and hydrological processes, as well as the awareness of the wide spatial and temporal scales in which these processes take place, have increased the need for accurate and continuous three-dimensional descriptions of topography (Lane et al., 1998). A detailed description of fluvial topography is also essential to accurately model the extent of the flooded areas. Therefore, the current concern regarding the impacts of climate change on the magnitude and frequency on flooding has also further increased the interest in this type of data (Rumsby et al., 2008).

Currently, the most accurate method for collecting elevation data for the production of digital elevation or terrain models (DEMs or DTMs) is laser scanning or LiDAR (light detection and ranging or laser induced direction and ranging; Cavalli et al., 2008; Marks and Bates, 2000). The first laser instruments were built in the 1960s (Maiman, 1960; Smullins and Fiocco, 1962), with the first laser instrument for distance measurements invented in 1966 (Price and Uren, 1989). Non-scanning LiDAR systems were used for bathymetry, forestry and other applications in the 1970s and 1980s (Guenther, 2007; Nelson et al., 1984; Schreier et al., 1985; Solodukhin et al., 1977), which established the basic principles of using lasers for remote sensing purposes. The first experiments with modern laser scanner instruments were conducted in the early 1990s, and the first prototype of a commercial airborne laser scanning (ALS) system dedicated to topographic mapping was introduced in 1993. For more information on the early development of ALS systems, see Bufton (1989), Flood and Gutelius (1997), Lohr and Eibert (1995) and Wever and Lindenberger (1999).

LiDAR data have been widely applied in environmental sciences, for example in topographic mapping and elevation modelling (Huising and Gomez Pereira, 1998; Kraus and Pfeifer, 1998; Sithole and Vosselman, 2004), mapping of coastal bathymetry (Irish and Lillycrop, 1999; Irish and White, 1998; Parson et al., 1997), fault structures (Candela et al., 2009; Harding and Berghoff, 2000; Wechsler et al., 2009), gully erosion (Jackson et al., 1988; Perroy et al., 2010; Ritchie and Jackson, 1989), vegetation characterization (Hyyppä et al., 2001, 2008; Lim et al., 2003), change detection of the thickness and extent of ice sheets and glaciers (Hopkinson et al., 2010; Krabill et al., 1999; Wadhams and Wallis, 1995), atmospheric studies (Bissonnette et al., 1997; Burton et al., 2010; Lawrence et al., 2010) and the vectorization of buildings (Brenner, 2005; Kaartinen and Hyyppä, 2006; Maas and Vosselman, 1999). In a fluvial environment, laser scanning was applied for the first time in 1984, when the applicability of ALS for mapping the cross-section of a floodplain was investigated by Krabill et al. (1984). Since then, airborne and terrestrial LiDAR data have been used to improve, for example, the accuracy of fluvial sediment dynamics analyses (Milan et al., 2007; Morche et al., 2008; Rhoades et al., 2009; Thoma et al., 2005), as well as the mapping of alluvial and fluvial landforms (Carey et al., 2006) and the extent of inundation (Alho et al., 2009a; Cook and Merwade, 2009). In addition, attempts have also been made to apply very fine-resolution close-range laser scanning to describe riverbed surface characteristics in flume experiments (Packman and Brooks, 2001; Packman et al., 1997; Rumsby et al., 2008).

Compared to the traditional methods used for the acquisition of topographical data, such as theodolite or tachymeter measurements, the ALS systems provide a more spatially extensive, economical and rapid approach (Charlton et al., 2003; Pereira and Wicherson, 1999). Compared to the other remote sensing techniques, such as optical aerial and satellite imagery, the advantages of laser scanning include the ability to measure surface elevations under the canopy cover (Hollaus et al., 2005; Kraus and Pfeifer, 1998) and its non-dependence on lighting conditions (Baltsavias, 1999a). Although ALS 

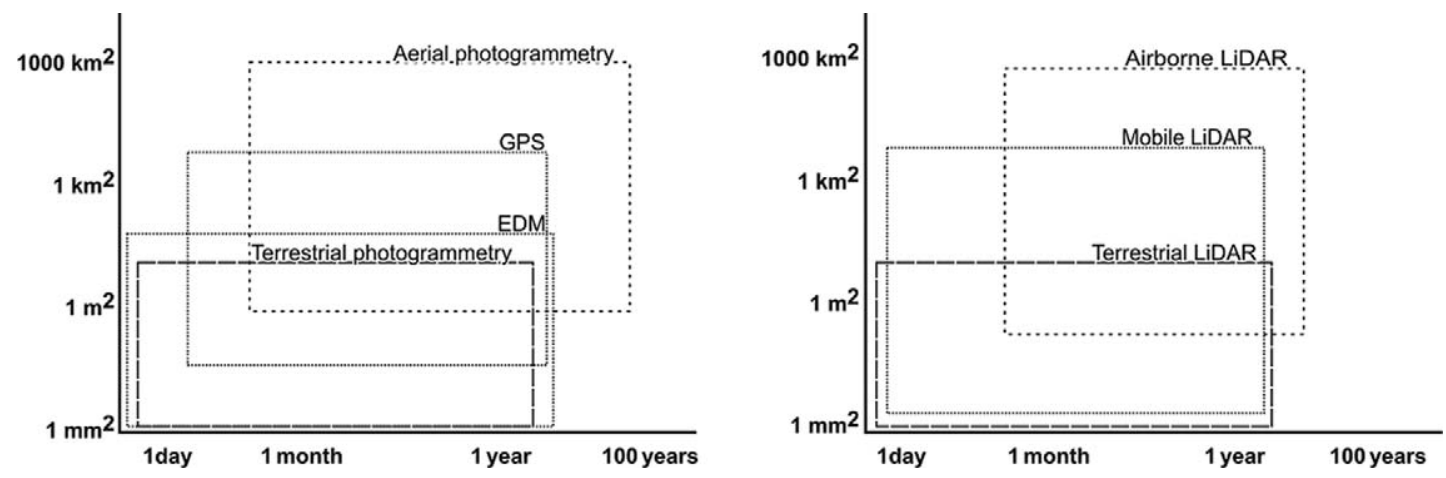

Figure I. Spatial and temporal limits of different traditional (left) and laser scanning methods (right) Source: After Heritage and Hetherington (2007: Figure I, p. 67)

methods do not generally achieve the same elevation accuracy as terrestrial approaches, accuracies of less than $10 \mathrm{~cm}$ have been reported using ALS for modulating vegetated terrain (Hyyppä et al., 2005). ALS is also a costeffective technique: $10-30 \mathrm{~cm}$ accuracy can be obtained at a cost of $10-15 € / \mathrm{km}^{2}$ for large areas $\left(>100,000 \mathrm{~km}^{2}\right)$. Terrestrial laser scanning (TLS) is also used routinely for mapping river environments when the required spatial resolution varies from grain scale $\left(<10^{-2} \mathrm{~m}^{2}\right)$ to reach scale $\left(>10^{2} \mathrm{~m}^{2}\right)$. For example, compared to traditional stereophotogrammetry, TLS is more rapid, easier to use and has automated postprocessing and error-checking (Hodge et al., 2009b; Milan, 2009; Milan et al., 2007; Rumsby et al., 2008). A comparison of the spatial and temporal limits of the different techniques used for surveying topography is given in Figure 1.

In this paper, we will evaluate the applicability of different LiDAR methods in fluvial studies. First, we give a short overview of the operation principles of different LiDAR systems. Second, we describe the steps needed to produce a DTM from LiDAR point elevation data and discuss the effects of floodplain land cover and surface sediment characteristics on the accuracy of LiDAR data. Third, we present a review of LiDAR applications in fluvial studies. Finally, we conclude with the state of the laser scanning applications in fluvial studies and some potential future developments.

\section{Laser scanning methods for topographical data acquisition}

Currently, several types of laser scanning method applications are used in fluvial studies (Figure 2). The airborne approach is most suitable when long reaches are being studied. Along with topographical data, airborne bathymetric measurements have also become available. By comparison, when more accurate data on surface microtopography are needed, terrestrial laser scanning provides a better option. The mobile boat-based version of terrestrial laser scanning has been developed to map larger spatial areas, and also gives a better description of the riverbanks from the river perspective. The highest resolution is obtained with close-range laser scanners. The following sections present some technical characteristics, which determine the suitability of the different LiDAR methods for different research purposes. A summary of the typical features of LiDAR systems is given in Table 1.

\section{Airborne laser scanning (ALS)}

ALS acquires range measurements and their precise orientation from an airborne platform 


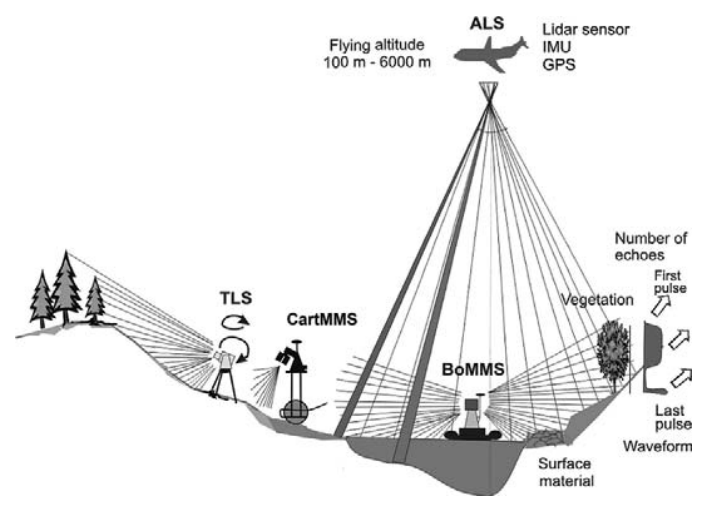

Figure 2. Laser scanning methods used in fluvial studies and factors affecting the accuracy of the elevation measurements. Airborne laser scanning (ALS) can be used to map riverine topography and bathymetry over extensive areas. More detailed data of the topography and land surface properties are obtained by terrestrial laser scanning (TLS). MLS, including boat- and cart-based mobile mapping systems (BoMMS, CartMMS), may be used to expand the spatial extent of the scanning process on the ground. ALS and MLS consist of GPS, IMU and laser scanner sensor, while TLS includes only the sensor. Hence, the absolute position of TLS has to be measured with external GPS.

(Figure 2). Typically, short infrared laser pulses (4-10 ns) are emitted at a high frequency (50$400 \mathrm{kHz}$ ) and deflected continuously in an across-flight direction using various scanning methods. The position and orientation of the laser sensor are continuously recorded along the flight path with a Global Positioning System (GPS) and an Inertial Measurement Unit (IMU). The recorded range, together with beam deflection, sensor position and orientation can be converted into a georeferenced three-dimensional (3D) point cloud representing the geometry of surface targets.

The first commercially available airborne laser scanners only recorded the time of one backscattered pulse to determine the range from the sensor to the target. With these so-called first-pulse LiDAR systems, it was not possible to make a distinction between the pulses returned from different objects (Marks and
Bates, 2000). State-of-the-art commercial laser scanners typically measure about 4-5 pulses (i.e. multiple pulses) and are thus able to separate different objects within the travel path of the laser pulse. Pragmatically, over forested terrain one may thus assume that the first pulse is mainly associated with the top of the canopy, while the last pulse probably corresponds to the ground elevation (Large and Heritage, 2009). Correspondingly, from flat surfaces only a single pulse is obtained.

The intensity is often recorded for each point representing the measured power or amplitude of the received pulse or waveform. Since intensity is affected by the flight parameters together with the object properties, the former need to be calibrated out. For single pulses, this is possible with non-waveform ALS. The purpose of this so-called relative calibration is to make the measurements from different altitudes, incidence angles and dates comparable for the same system, whereas absolute calibration aims at a value that describes purely the target scattering properties and which also cancels out the atmospheric and other non-instrumental effects. Thus, the basic idea in radiometric calibration is to absolutely correct the returned pulse power or waveform amplitude into parameters equal or proportional to the surface reflective properties. For more information about intensity calibration, the reader is referred to Ahokas et al. (2006), Coren and Sterzai (2006), Höfle and Pfeifer (2007), Kaasalainen et al. (2009), Wagner (2010) and Wagner et al. (2006).

More recently, small-footprint waveformdigitizing ALS systems have also become available, which record the whole laser backscatter return as a function of time (Wagner et al., 2006). The use of waveform in ALS allows advantages such as the improved radiometric calibration of backscatter since it is impossible to accurately calibrate the intensity value of returns having multiple pulses (Wagner, 2010). In addition, such waveform systems also allow improvement in the accuracy of both elevation 


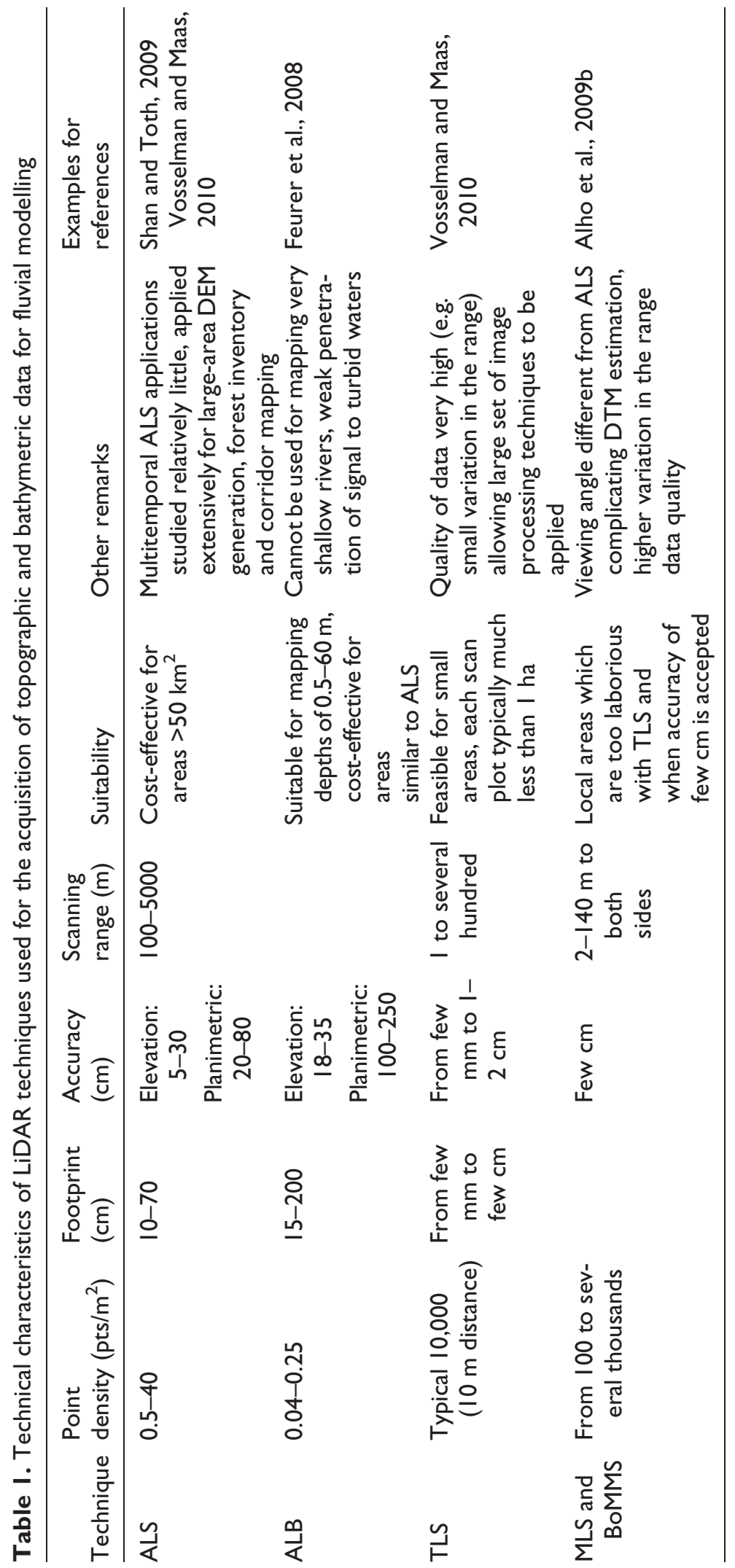


modelling (Doneus et al., 2010) and object classification. Since fluvial geomorphology benefits from these improvements, the use of waveformdigitizing ALS in fluvial geomorphology research needs further studies.

\section{Airborne LiDAR bathymetry (ALB)}

Technical developments have enabled the use of airborne LiDAR systems in bathymetric measurements (Hilldale and Raff, 2008). The bathymetric LiDAR is based on the use of blue-green wavelengths, which can better penetrate deep water. Longer wavelengths cannot be used, because they are absorbed by water, while shorter wavelengths would be scattered and absorbed by water-borne particles (Wang and Philpot, 2007). The calculation of distances from the LiDAR sensor to the bottom is based on the travel time of the return signals and the known speed of light in water and in air.

Although, ALB was developed in the late 1960s (Hickman and Hogg, 1969), it was not possible to overcome the accuracy problems for bathymetric measurements caused by the variation of the water surface elevation until the improvements of the GPS, at the end of 1990s. ALB was originally developed for mapping coastal bathymetry (Guenther et al., 2000) and most scientific literature published so far has focused on this application in coastal areas, while similar research in fluvial environments remains rather limited (Allouis et al., 2007; Feurer et al., 2008).

\section{Terrestrial laser scanning (TLS)}

To acquire a more accurate description of the topography of the scanned area, laser scanners can also be mounted on a tripod situated on a riverbank (Figure 2). Such a fixed-position TLS offers high potential for the 3D mapping of smaller areas with high detail, a range accuracy of up to $1-2 \mathrm{~mm}$ and a scanning speed of up to $1 \mathrm{M} \mathrm{pts} / \mathrm{s}$. The principle of TLS is simple, involving highly collimated laser-beam scans over a predefined solid angle in a regular scan pattern and the measurement of the time of flight of the laser signal. The scanning range of the typical so-called "middle-range terrestrial system' (TLS are typically divided into three groups based on their ranging capability) allows distance measurements between 2 and $800 \mathrm{~m}$. The potential of terrestrial laser scanning is supported by simultaneously combining exposed digital imagery. By combining these two data sources, the shapes of 3D transportation features can be determined more accurately because the laser point clouds are projected onto the digital images simultaneously (Balletti et al., 2003; Rönnholm et al., 2003). Compared to ALS, TLS is a cheaper method for small areas and allows higher-resolution and precision mapping of terrain features (Alho et al., 2009b). It is particularly useful for the detection of small-scale fluvial features, such as point bar structures, dunes and ripples.

\section{Mobile laser scanning (MLS)}

One disadvantage of static TLS is that data collection is spatially rather limited, a problem which may be overcome using mobile terrestrial laser scanning (Kukko et al., 2007). One of the newest applications is a boat-based, mobile mapping system (BoMMS) (Alho et al., 2009b) (Figure 2). The boat-mounted mobile laser scanner is a multisensor system that integrates various navigation and data acquisition sensors on a boat for collecting point clouds along the river line. The instrumentation of the BoMMS is similar to that used in airborne surveys. Due to the longer periods used for recording the data, the amount of information produced by mobile systems is huge. Consequently, the manual processing of the data is time-consuming, which has prompted the need for automated methods that decrease the amount of work required to produce accurate 3D models. Although it is possible at present to use both software and methods developed for terrestrial and airborne laser scanning, 
specific algorithms for data processing also need to be developed separately, due to the different scanning geometry, point density and the fast processing time needed (Jaakkola et al., 2008).

Compared to static TLS, mobile laser scanning is a more effective and faster mapping method because duplicate measurements of the same areas can be avoided and the direct georeferencing of scans with the GPS-IMU system reduces the post-processing time (Alho et al., 2009b, 2011; Zhao and Shibasaki, 2003). The quality of boat-mounted laser scanning is limited by the accuracy and quality of the GPS and IMU measurements. Since the distances are short, the main errors derive from GPS positioning. This is particularly true for fluvial environments, where forest cover may further reduce the accuracy of the GPS. Thus, the quality of mobile laser scanning is comparable to ALS and in controlled conditions may achieve an accuracy of 2-4 cm using improved georeferencing and calibration of the systems (Kaartinen et al., forthcoming). Nevertheless, compared to ALS, the utilization of static TLS and MLS in fluvial studies are more feasible for local studies.

\section{DTM creation for fluvial studies}

\section{Processing point cloud data and DTM production}

To accurately model the flow of water over the floodplain, the DTM derived from the LiDAR point data must preserve all of the important geometric details affecting the flow. The production of a hydraulically functional DTM from the raw LiDAR point cloud requires a series of steps (Figure 3). First, the point cloud data need to be georeferenced and the points classified into the right surface categories. Then the point data must be interpolated to produce a continuous surface. To model the water flow accurately, it has also been recommended to include the channel bathymetry in the model, as well as the objects that affect the direction and velocity of water flow in the over-bank situation, such as buildings (Mandlburger et al., 2009).

\section{Georeferencing of the LiDAR point data}

For georeferencing of each scan, the sphere target should be detected from the MLS data and a template sphere of fixed radius should be matched to the selected points and reflected from the target to find its centre point (cf. Alho et al., 2011). To ensure that gross errors are removed, the measured and matched sphere coordinates are compared. Subsequently, the scans should be transformed to global coordinates, according to the measured scanner and sphere target locations. The RTK-GPS data have been applied to georeference the laser scan data. The achievable accuracy of RTK-GPS measurements is $1 \mathrm{~cm}+$ 1-2 ppm horizontally and $1.5-2 \mathrm{~cm}+2$ ppm vertically (RMSE) (Bilker and Kaartinen, 2001). The concept of strip adjustment (determining discrepancies between overlapping scan strips) is normally applied before the laser scan data underwent filtering and classification.

\section{Point filtering and classification}

The raw LiDAR point cloud consists of returns from different kind of surfaces. To produce an accurate DTM, it is essential to differentiate the ground returns from other points. Sometimes, when Digital Surface Models (DSMs), Canopy Height Models (CHMs) or normalized Digital Surface Models (nDSMs) are being created, the separation between points returned from different land cover types is also required. Point cloud coordinates, echo type and width, reflectance and the time information recorded to laser points can be used to classify the points into different surface categories. Several algorithms have been developed for the classification of ground points, the most common of which are described below. Kraus and Pfeifer (1998) developed a DTM algorithm for which laser points between terrain and non-terrain points were distinguished using an iterative prediction of the DTM. Here, 


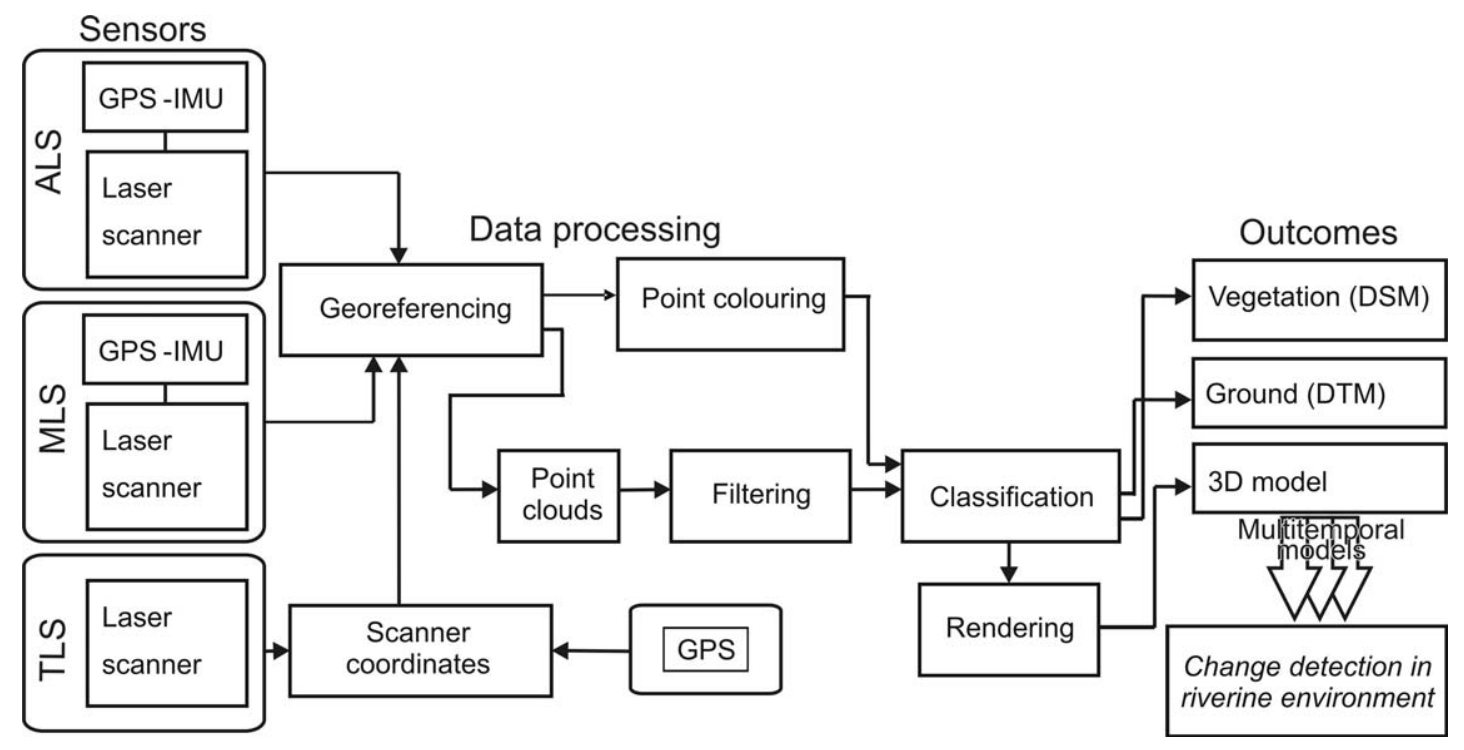

Figure 3. LiDAR data processing. LiDAR data are georeferenced with internal GPS-IMU data in the case of ALS and MLS. External scanner coordinates from a GPS survey are more common in TLS surveys. A similar processing of the point cloud is normally utilized for all LiDAR data, including creating the point cloud, filtering and classification. Classified LiDAR points can be transformed into DSMs, DTMs and 3D virtual models. Change-detection studies can be made with multitemporal data.

Source: Adapted from Alho et al. (201 I).

weights were attached to each laser point, depending on the vertical distance between the expected DTM level and the corresponding laser point. Further improved by Kobler et al. (2007), this method has also been implemented in commercial software known as $\mathrm{SCOP}++$ (Kraus and Otepka, 2005). The other well-known commercial method (Terrascan) is based on the work of Axelsson (2000), based on a progressive TIN densification method. Here, the laser point cloud is first classified into ground and other points. The program selects the lowest local points as the initial ground points from a large grid (e.g. using $80 \times 80 \mathrm{~m}$ grid) and makes an initial triangulated model. New laser points are then added to the model iteratively if they meet the assigned criteria. A thorough comparison of the filtering techniques used for DTM extraction can be found in a report on ISPRS (International Society of Photogrammetry and Remote Sensing) comparison of filters (Sithole and Vosselman, 2004). Selecting a filtering strategy is not a simple process because, in practice, the amount of interactive work determines the final quality of the product.

\section{Data reduction}

According to Mandlburger et al. (2009), before the production of a DTM is possible in a conventional flow modelling context, the large amount of data gathered with laser scanning first needs to be reduced. Mandlburger et al. (2009) presented an adaptive TIN refinement method, which can be used to create a mesh suitable for numerical hydrodynamic modelling. The method is applied onto the filtered hybrid DTM consisting of a regular grid, break lines, structure lines and spot heights. The algorithm first creates an approximation of the DTM by triangulating structure and a coarse regular grid. The maximum height error is used as a limit when the grid cells are refined by inserting additional grid points either hierarchically or irregularly. After 
refinement, the generated mesh is conditioned by taking into account the physical phenomena being simulated, such as flow direction and bed shear stress.

\section{Effects of land cover and sediment surface properties on the accuracy of LiDAR data in a fluvial environment}

Riverine environments are mixtures of different surface types and geomorphological features. Water, vegetation, steep riverbanks and different forms of sediment surfaces, varying from fine material to large boulders, all have characteristics that may produce errors to the DTMs derived from laser scanning data (Hodgson and Bresnahan, 2004; Hodgson et al., 2003) (Figure 2).

Riverbanks and floodplains are often covered by grasses and shrubs and even tall trees may be present. In several studies, it has been observed that the taller and, in particular, the more dense the vegetation, the larger the elevation errors in LiDAR data, because a lower number of laser pulses is reflected from the ground surface (Charlton et al., 2003; Heritage and Hetherington, 2007; Hodgson et al., 2003; Hyyppä et al., 2005; Reutebuch et al., 2003). In the study of Heritage and Hetherington (2007) a mean residual error of $0.07 \mathrm{~m}$ was found between the oblique TLS data and EDM theodolite points collected on ground surface areas covered by broad-leaved vegetation. The scanning accuracy on the grass-covered surfaces was generally more variable, and the authors suggested that this was to be due to lower leaf density and more diffuse leaf structure, which allowed some of the laser beams to reach the ground. In addition, low dense vegetation also makes the differentiation of laser returns between ground and nonground points more difficult (Straatsma and Middelkoop, 2006), possibly causing a 'labelling error' (Hodgson and Bresnahan, 2004). In ALS, the minimum distance between the first and last returns that allows them to be registered separately is $1.5 \mathrm{~m}$ (Baltsavias, 1999b). For example, Overton et al. (2009) reported approximately $1 \mathrm{~m}$ elevation errors caused by the misinterpretation of laser returns from dense reed beds as ground returns, while Takeda (2004) reported even greater errors up to $20 \mathrm{~m}$.

The characteristics of the scanned sediment surface may also decrease the accuracy of grain-scale elevation data acquired with the high-resolution laser scanning systems. In the study of Heritage and Hetherington (2007), the best accuracies of TLS data were found across smooth bedrock surfaces (mean residual error $0.0065 \mathrm{~m}$ ), which are visible from several scan locations. By contrast, the laser data were less accurate (mean residual error $0.025 \mathrm{~m}$ ) on a heterogeneous cobble and boulder bed due to the shadowing effect of adjacent clasts. The adjacent clasts prevent the penetration of laser beams between the clasts, which leads to an overestimation of surface elevation. In particular, large errors were observed when the clasts were large, the gaps between them were narrow and when the angle of incidence of the laser pulse was low. This is similar to the observation made by Hodge et al. (2009a), who found obscured areas between grains in sediment surfaces. Due to the shadowing effect, it is not possible to obtain the full 3D presentation of the surface with a single scan. The data can be reduced to a 2.5D DTM in which each $\mathrm{x}$ and $\mathrm{y}$ location has a single elevation value. The $2.5 \mathrm{D}$ DTM has the same roughness characteristics as the 3D model, so it is suitable for fluvial studies (Hodge et al., 2009b). It has also been suggested that the same area should be scanned from multiple directions (Heritage and Milan, 2009) and the laser scanner placed as high as possible to minimize the shadowing effect (Heritage and Hetherington, 2007; Milan et al., 2010).

Heritage and Hetherington (2007) found that the accuracy of TLS point data did not depend on surface colour, the intensity of laser pulse reflection or the scanning distance. However, Hayakawa and Oguchi (2005) observed that 
during box type laser scanning some minerals of the gravel caused the laser beams to reflect incorrectly and produced holes in the resulting 3D polygon models of stones. Although some models were corrected with spatial interpolation; those samples with the largest holes had to be omitted from the analysis.

Water surfaces usually absorb or scatter infrared laser pulses rather than reflect them (Milan et al., 2010; Overton et al., 2009) and, therefore, deep water zones normally produce gaps in the LiDAR data (Charlton et al., 2003). In shallow, clear and calm water, with high angles of incidence, some penetration by infrared laser pulses may occur (Cavalli et al., 2008; Heritage and Hetherington, 2007; Milan et al., 2007). Nevertheless, the high level of turbidity and water surface disruption due to bed roughness may affect the returning signals. In their investigation of the accuracy of TLS data, Heritage and Hetherington (2007) found relatively large mean residual error of $0.2555 \mathrm{~m}$ on clear and calm water surfaces and mean residual error of $0.2359 \mathrm{~m}$ on water edges.

Steep riverbanks may cause problems for elevation measurements with ALS. The error budget model presented by Hodgson and Bresnahan (2004) showed that on steep slopes the horizontal error caused by the LiDAR system operation, in combination with other error sources, distorts the elevation measurements. This is consistent with the finding of Hyyppä et al. (2005) who observed that elevation errors of LiDAR-DTMs substantially increased on slopes greater than $15^{\circ}$ under the tree cover. The point density of ALS may also be so sparse that the riverbanks are not accurately described in the terrain model (Aggett and Wilson, 2009). Boatbased laser scanning (Alho et al., 2009b) solves the aforementioned problems as it allows detailed scanning of the riverbanks from the river channel aspect. This makes it a suitable method, for example, in flood studies, in which the knowledge of riverbank heights is essential (Aggett and Wilson, 2009).

\section{Application of LiDAR data in fluvial studies}

The following sections review the studies that use LiDAR data with varying accuracies and spatial resolutions in several fields of fluvial studies. Some papers cited here contain themes that cross the borders between the different fields. However, in Table 2, the key papers cited are classified under different fields according to the main focus of the study.

\section{Mapping of macro-scale fluvial landforms}

In several studies, the spatial resolution provided by ALS data has been found adequate for the visual recognition of macro-scale fluvial landforms, such as river channels, palaeochannels, alluvial fans, levees and valley edges (Aggett and Wilson, 2009; Frankel and Dolan, 2007; Jones et al., 2007; Notebaert et al., 2009). A semi-automated method for channel network extraction from ALS data has also been proposed (Mason et al., 2006). LiDAR surveys have also made it possible to draw detailed onedimensional profiles of river reaches, which can be used to distinguish step-pool, riffle-pool and mixed morphological units of the river channel (Cavalli et al., 2008). The surface roughness values derived from ALS data have also been used for the classification of morphological units of the channel bed (Cavalli et al., 2008) and for the detection of old alluvial fans (Frankel and Dolan, 2007). ALS data have also been used in assessing the pattern and characteristics of hydrological facets, which act as single hydrological units in low-relief landscapes (Jones et al., 2008). The distinct advantage of the LiDAR data is that they enable more accurate and detailed mapping of fluvial landforms compared to lower-resolution elevation data. It also allows faster mapping of larger areas than is possible with field surveys.

The extent to which the fluvial landforms can be detected from elevation models derived from 


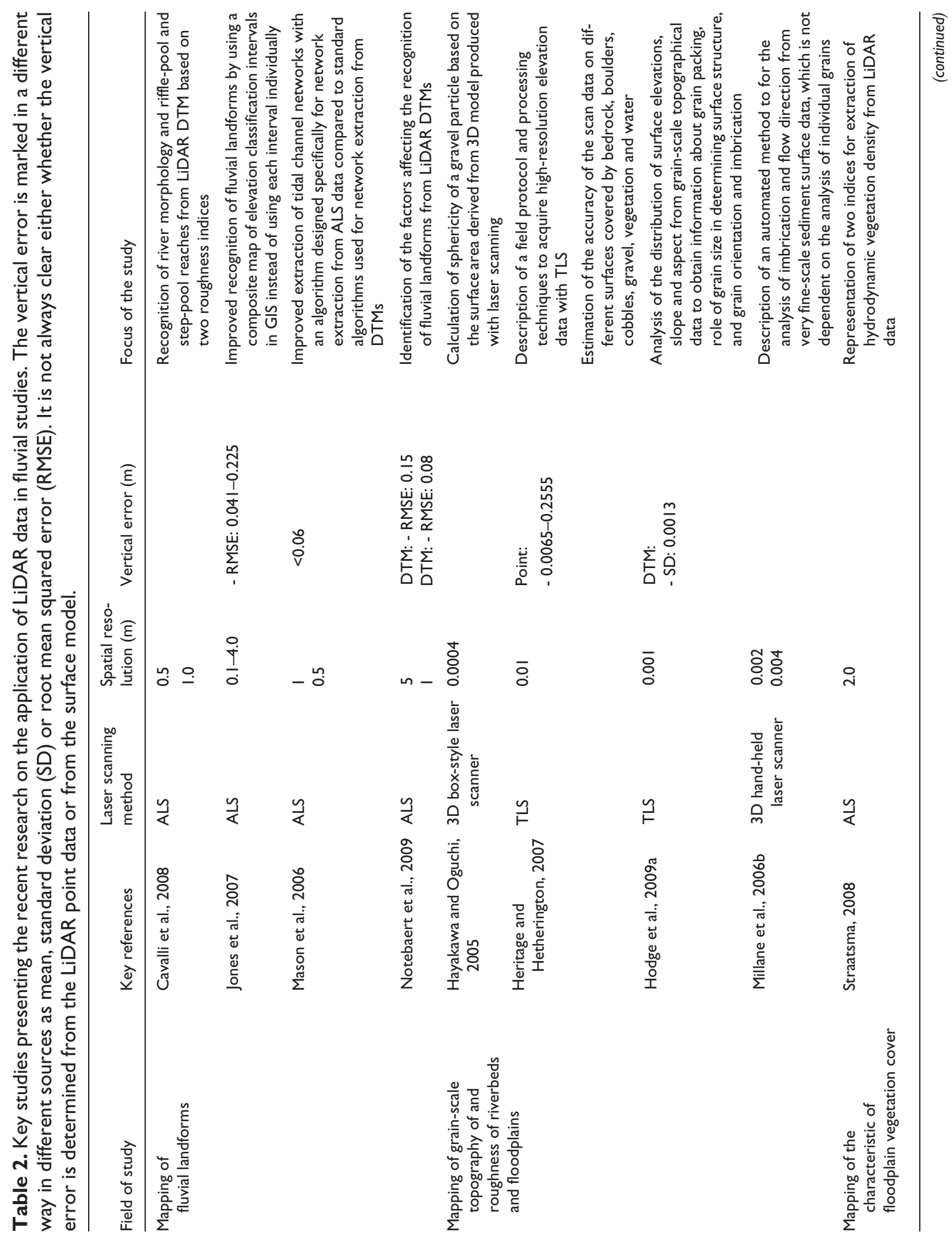




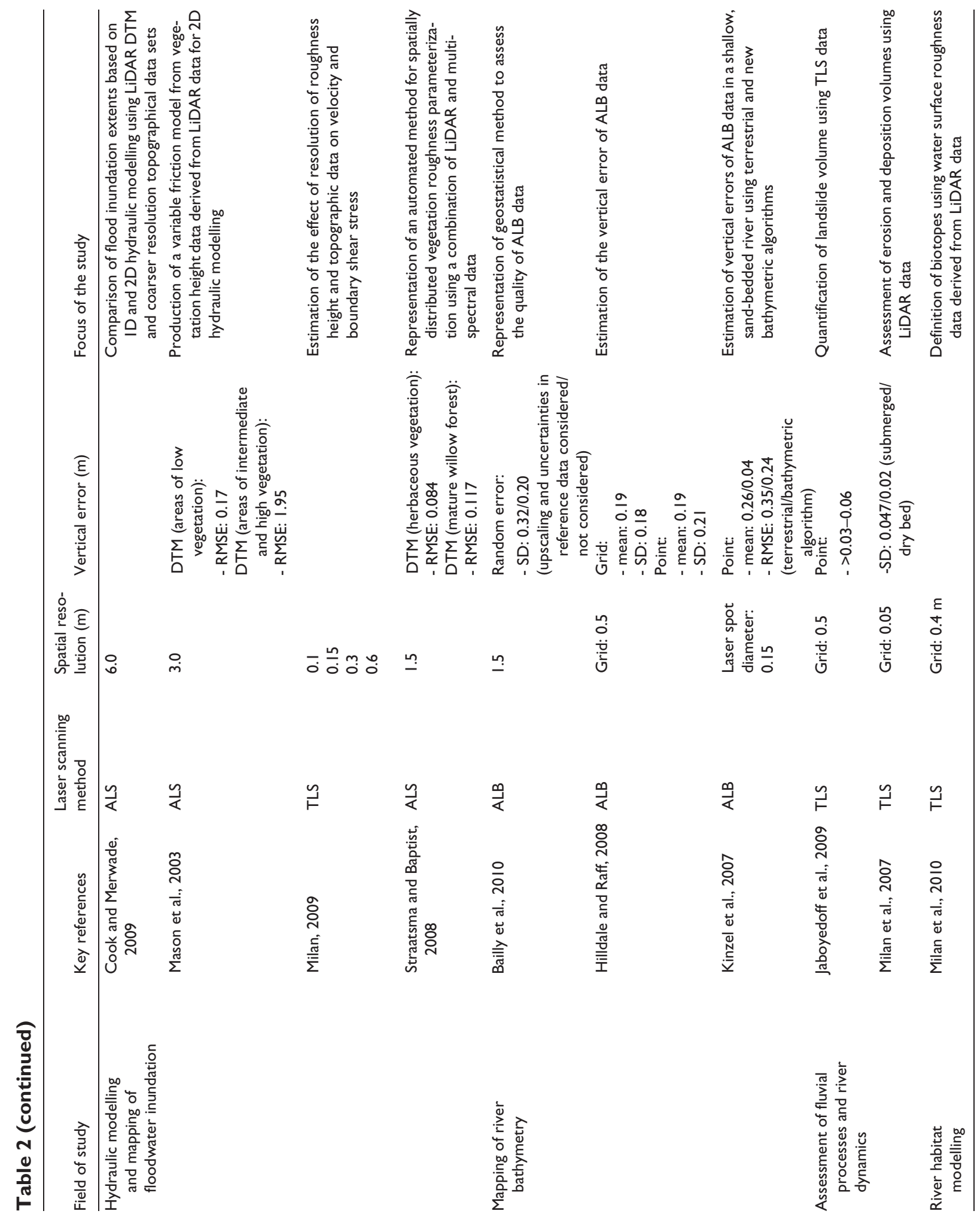


ALS data is, however, affected by several factors. First, the number of measured elevation points per unit area in the original LiDAR data is important, because a higher point density leads to a better visibility of the smaller-scale elevation variation in the DTM created by interpolation (Notebaert et al., 2009).

Second, the use of automated data filtering techniques applied to LiDAR data may disrupt the identification of landforms, because the data gaps left by removed vegetation and buildings have to be compensated by interpolated data (Jones et al., 2007). In these cases, the use of unfiltered data may be more useful.

Third, the vertical error and spatial resolution of the data determines the minimum size of the features that can be identified (Notebaert et al., 2009). If the height difference of a feature compared to the surrounding floodplain is smaller than the randomly distributed vertical errors of the elevation data, the feature may not be detected. Moreover, it is impossible to detect features that are smaller than the grid cell size of the LiDAR DTM used. For example, using a LiDAR DTM with a spatial resolution of $5 \mathrm{~m}$, Notebaert et al. (2009) were able to identify only the largest features, such as levees (width $50-200 \mathrm{~m}$, height difference $0.2-1.5 \mathrm{~m}$ ) and the largest palaeochannels (width $\geq 10 \mathrm{~m}$ ). By comparison, with a $1 \mathrm{~m}$ resolution, it became possible also to recognize small drainage ditches and shallow depressions (depth $<0.8 \mathrm{~m}$, width $<10->20 \mathrm{~m}$ ). Furthermore, the authors noticed that the data visualization, particularly the hill shade mapping, can improve the recognition of landforms from LiDAR DTMs.

The fourth issue in fluvial landform mapping relates to the geomorphological setting of the studied area. For example, the recognition of old abandoned channels with small height differences is usually more difficult than the detection of current river channels in a more dynamic environment (Notebaert et al., 2009). In particular, when the relief of the studied area is relatively smooth, the interpretation of the geomorphological features still requires additional information collected in the field (Jones et al., 2007; Notebaert et al., 2009). Therefore, ALS data should not totally replace the traditional field surveying techniques in these cases.

Finally, when landform recognition is undertaken by classifying the elevation data provided by LiDAR DTMs in GIS, the classification interval used affects the ability to differentiate between landforms. Jones et al. (2007) recommended that the range of classification intervals should be fitted to the relative relief of the studied area, so that it would be possible to distinguish features, whose sizes vary in different vertical scales. In their study, they noticed, for example, that the use of smaller classification intervals allowed a better recognition of alluvial fan margins and palaeochannels, while larger classification intervals were more suitable for the recognition of valley edges. Instead of using each of the intervals individually, the use of a composite map of six classification intervals $(4,2,1,0.5,0.25$ and $0.1 \mathrm{~m})$ also resulted in the recognition of larger feature lengths as well as increasing the accuracy of feature positioning.

\section{Mapping of grain-scale topography of riverbeds and floodplains}

The study of micro-scale fluvial topography and the determination of size, shape and orientation of the particles of the riverbed and floodplain surface material are crucial elements of those studies aiming to understand the water flow and the transport of the sediments in a river channel. Recently, the development of TLS has enabled the identification of grain-scale fluvial morphology with a higher spatial resolution than has been possible previously with physical profilers (Hodge et al., 2009a, 2009b). TLS is also a noticeably faster method than grain sampling (Entwistle and Fuller, 2009). Although a resolution of millimetres can be achieved with TLS, it has been recommended to study centimetre- 
scale grains, otherwise the topographic variation may be lost in data noise (Hodge et al., 2009a). By analysing the distribution of surface elevations and surface slope and aspect from detailed DTMs derived with TLS data, Hodge et al. (2009a) were able to obtain useful information about the sizes, packing, orientation and imbrication of sediment grains of gravel surfaces. On very fine sediment surfaces, where the grain scale cannot be reached with TLS, mapping of the height, length, orientation and volume of the ripples and dunes is possible (Alho et al., 2009b).

Even the characteristics of millimetre-scale grains can be studied with three-dimensional close-range laser scanners (Hayakawa and Oguchi, 2005; Millane et al., 2006a, 2006b). For example, Hayakawa and Oguchi (2005) evaluated bar gravel shape parameters from the 3D model acquired with a box-style laser scanner designed for laboratory use. The 3D models produced allowed the determination of volume and surface area as well as the three axes of the gravel particles, which can be used to compute indices for both sphericity and particle settling velocity. In particular, the measurement of data of the gravel particles' surface area, which was previously almost impossible to attain with manual methods, was found useful for the calculation of the gravel-shape parameters.

\section{Mapping of the characteristics of floodplain vegetation cover}

In addition to the sediment surface characteristics, the vegetation cover of the floodplain also affects the water flow, especially in areas of shallow inundation during flooding (Mason et al., 2003). The magnitude of this effect is particularly dependent on the density of the emergent vegetation (e.g. trees), including the density and height of the submerged vegetation (e.g. grassland and herbs) (Straatsma and Middelkoop, 2006). LiDAR data are able to provide information on spatially distributed vegetation heights and densities (Straatsma and Baptist, 2008).

Cobby et al. (2001) and Mason et al. (2003) described a range image segmentation system for the estimation of the vegetation heights from ALS data. This semi-automatic system assumes that the minimum heights within each $3 \mathrm{~m}$ grid cell represent the ground return points, whereas the maximum heights represent points reflected from the vegetation cover. Using the minimum and maximum heights, the system produces raster images of surface topography and vegetation height. The vegetation surface is subtracted from the land surface and the standard deviations are calculated from $15 \times 15 \mathrm{~m}$ windows, which are centred on each pixel. From this standard deviation image regions of short $(<1.2 \mathrm{~m})$, intermediate and tall $(>5.0 \mathrm{~m})$ vegetation are separated. The shortest vegetation class includes most agricultural crops and grasses, the intermediate class includes hedges and shrubs, and the tallest class includes trees. This segmentation system then allows different algorithms to extract surface and vegetation heights depending on the land cover.

Straatsma and Middelkoop (2006) pointed out that the time of the year has a significant effect on the detection of vegetation heights from LiDAR data. In summer, or during the rainy season in semi-arid tropical areas, the reflection intensity of laser pulses from the vegetation is higher and the laser beams do not penetrate very deeply into deciduous and evergreen vegetation. In winter, or during the dry season, the reflection intensity of deciduous vegetation is lower and the laser beams are able to penetrate deeper into the canopy. This results in very different returned waveforms and point distributions in different seasons (Figure 4). Varying the reflection intensity threshold at which the laser pulses are registered may cause large differences in the recorded vegetation height. Moreover, during leaf-free periods, the vegetation surface area from which laser pulses are reflected is smaller. To get a proper picture of 
the floodplain vegetation roughness during flooding conditions, Straatsma and Middelkoop (2006) suggested that floodplain vegetation height measurements should be carried out during the season when the chance of flooding is highest.

Using ALS data collected in a deciduous lowland floodplain forest during leaf-free conditions, Straatsma (2008) assessed the potential of mapping hydrodynamic vegetation density, i.e. the horizontal obstruction of the vegetation for flowing water. The density was measured in the assumed flood inundation height interval. The lower end of the interval was set to $0.5 \mathrm{~m}$ to avoid the effect of noise of the ground surface points. The upper end was set to $2.5 \mathrm{~m}$, to be well above chest height where the density values are normally measured in field studies. Two indices to predict vegetation density were developed. The percentage index (PI) calculates the percentage of laser returns, the heights of which fall within the flood inundation height interval. The second index, the Vegetation Area Index (VAI), takes into account the occlusion from tree crowns, i.e. the reflection of laser pulses from tree branches, which decreases the number of pulses that are reflected from stems or the ground surface. This index shares the same assumptions of the occlusion mechanism with the Leaf Area Index (LAI) that can be calculated during periods of full leaf cover. The results showed that the density estimates given by the PI are similar to or more accurate than those derived from lookup tables determined for each ecotype. This latter 'ecotype approach' has been used, for example, in the Netherlands.

However, using ALS data to map the height and density of the lowest vegetation cover types, such as meadows, may be especially problematic, because it has a high standard deviation $(4 \pm 30 \mathrm{~cm})($ Davenport et al., 2000) and a large prediction error $(14 \mathrm{~cm})$ (Cobby et al., 2001). Therefore, it may still be necessary to derive the hydrodynamically relevant surface characteristics for such land cover classes from lookup tables (Straatsma and Baptist, 2008).

\section{Hydraulic modelling and flood inundation mapping}

As shown in sections 1-3 above, laser scanning applications are capable of providing detailed descriptions of the riverbed and floodplain landforms, grain-scale topography and vegetation characteristics, all of which influence the water flow. Consequently, high-resolution LiDAR data have increasingly been used to improve the performance of 1D (Aggett and Wilson, 2009; Gueudet et al., 2004; Omer et al., 2003) and 2D hydraulic models (Bates et al., 2003; French, 2003; Marks and Bates, 2000; Straatsma and Baptist, 2008).

The grain-scale information derived from high-resolution DTMs can be used for the estimation of grain-scale surface roughness of a riverbed, which is an essential parameter for river flow modelling. Traditionally, hydrodynamic models have relied on global roughness estimates derived indirectly from the timeconsuming measurement of grain-size distributions (Heritage and Milan, 2009; Milan, 2009) based on the length of the intermediate b- or c-axis of a 100-clast sample from a geomorphological unit (Wolman, 1954) or from photography (Ibbeken and Schleyer, 1986). However, previous research has revealed great advantages in the use of high-resolution roughness data derived from terrestrial laser scanning. Milan (2009) determined the local standard deviation of subareas across the raw TLS point cloud using a $3 \times 3$ moving window and multiplied the data by two to obtain estimates of the clasts' c-axis. The DEMs derived from this data were used to characterize the surface roughness in the hydraulic model. The study showed that the finer resolution of roughness height leads to a better prediction of modelled flow velocity, with more detailed flow deflection around roughness elements and a larger variation of flow velocities than coarser roughness resolutions. The distinct advantage of TLS-derived roughness data over the 
traditional sampling methods is that it takes into account the spatial variability in surface roughness (Milan, 2009), as well as the effect of imbrication and burial on the roughness factor of individual clasts (Heritage and Milan, 2009). Very high-resolution elevation data provided by the close-range laser altimeter could also be used to measure surface roughness (Butler et al., 1998; Rumsby et al., 2008). However, so far this potential has received only little scientific attention.

Mason et al. (2003) reviewed the methods to convert the vegetation heights derived from ALS data into friction factors at mesh nodes of a 2D flood model. In contrast to constant-friction models, which use a single friction value over the whole floodplain, the physically based variable-friction models avoid the non-physical fitting of floodplain and channel friction factors, and do not require recalibration when the same model is used with different input data for modelling different flood events. This is of particular importance when the models are used as predictive tools for forecasting the extent of flooding of hypothetical events from which observational data are unavailable. The extent of flood inundation produced using variable-friction models has also been shown to fit better to the observed flooding extents than that produced with constant-friction models (Cobby et al., 2003).

The improvement of the larger-scale topographic representation is also important, especially in mapping floodwater inundation on a floodplain, where the elevation variation affects the flow of shallow water (French, 2003). Highly generalized topographical data, such as those derived from the national topographic maps, may lead to a distorted perception of the floodwater levels and extents (Alho et al., 2009a; Cook and Merwade, 2009; Sanders, 2007). The spatial resolution of these data sources is typically coarser than the resolution of the model used (Bates et al., 2003). In a number of studies, the potential for using the high-resolution DTMs derived from LiDAR data for flood mapping has been investigated (Cook and Merwade, 2009; Overton et al., 2009; Wang and Zheng, 2005). The works by Cobby et al. (2003) and Cook and Merwade (2009) showed that the higher spatial resolution and better vertical accuracy of the DTMs tends to decrease the inundated area. By using a DTM derived from ALS data, Alho et al. (2009a) were able to map the locations and heights of road embankments and the flood inundation through single ditches.

The majority of the flood inundation studies have concentrated on rural areas. However, in recent years, LiDAR data have also proved useful in modelling flood hazards in complex urban areas where a high risk of economic and human loss makes the accurate estimation of floodwater extents and depths highly important. Laser scanning is able to provide detailed information on the complicated urban topography, and also allows distinctions to be made between surfaces with different kinds of hydraulic properties, such as roads, buildings and vegetated areas (Mason et al., 2007; Tsubaki and Fujita, 2010). However, because only those land cover classes with significant local height differences can be recognized from the LiDAR data (Straatsma and Baptist, 2008), it may still be inadequate to describe some of the complex details of the urban environment. There are several methods to improve the recognition of different land cover classes. These include combining the elevation data derived from laser scanning with digital maps and pattern recognition techniques (Mason et al., 2007), using multispectral remote sensing data (Straatsma and Baptist, 2008) as well as colour data derived from true colour orthophotos. In addition, unstructured grids representing the precise shapes of buildings (Tsubaki and Fujita, 2010), LiDAR intensity data (Oude Elberink and Maas, 2000) or normalized difference vegetation index (NDVI) extracted from near infrared spectral images may also be employed to improve recognition of land cover classes.

The incorporation of river bathymetry into topographical data sets has also been observed 


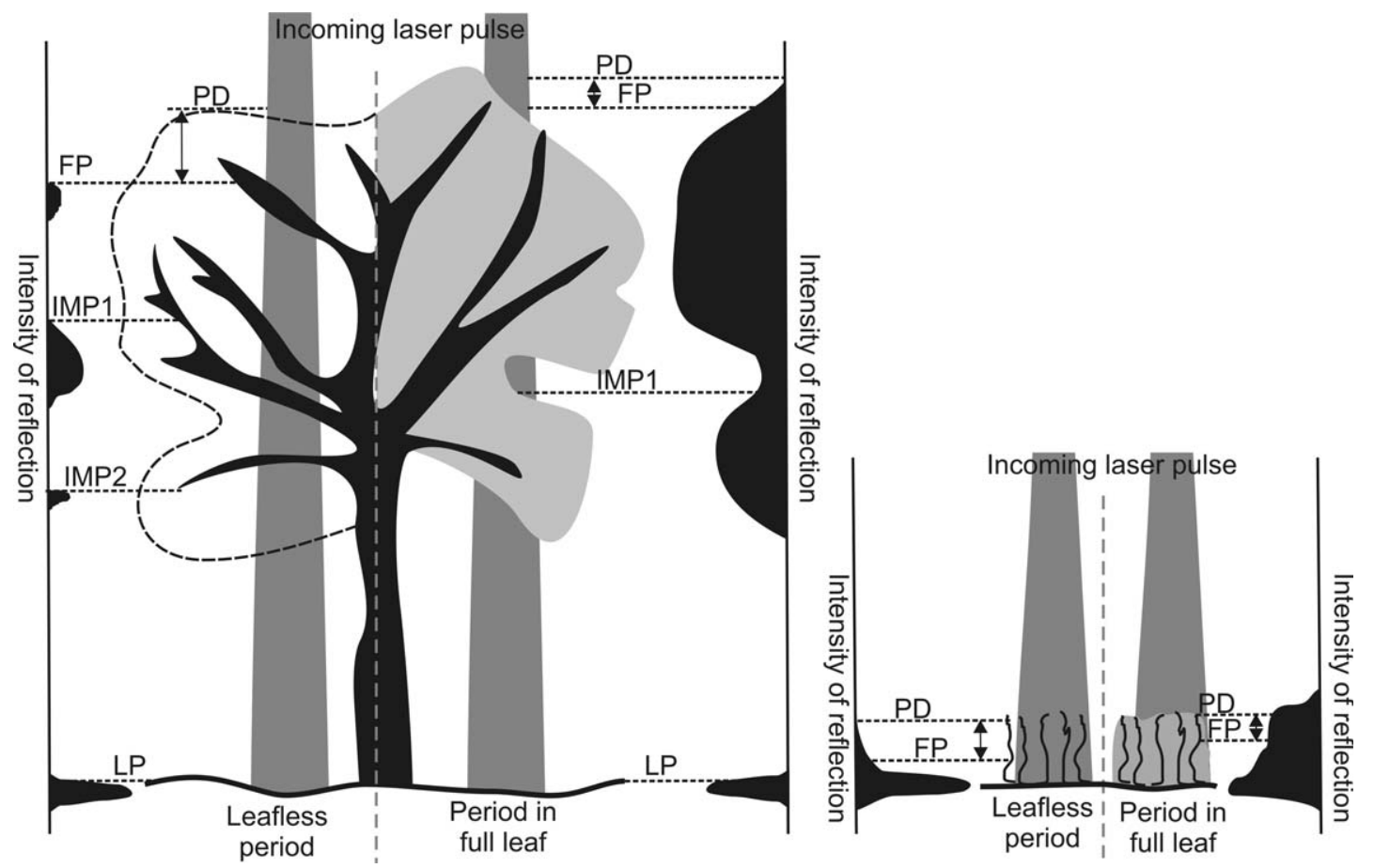

Figure 4. Laser reflection from trees on a riverbank (left) and herbaceous vegetation on a floodplain (right). The growing season has a significant impact on reflection and penetration of the canopy: intensity is higher and penetration is smaller during the period in full leaf than in the leafless period. FP = first pulse; IMP = intermediate pulse; $\mathrm{LP}=$ last pulse; $\mathrm{PD}=$ penetration depth.

Source: After Straatsma and Middelkoop (2006).

to affect the extent of the modelled floodwater inundation (Cook and Merwade, 2009). Thus far, such incorporated bathymetric data have been derived using data sources other than bathymetric LiDAR. For example, French (2003) integrated airborne LiDAR data with a composite bathymetric data set derived from echo soundings, electronic theodolite surveys and Ordnance Survey (OS) maps. Cook and Merwade (2009) and Mason et al. (2003) combined the topographic LiDAR data with river bathymetric data obtained from detailed channel cross-sections.

\section{Mapping of river bathymetry}

Various investigations on the applicability of airborne LiDAR bathymetry (ALB) in the riverine environment have been carried out (Allouis et al., 2010; Bailly et al., 2010; Hilldale and Raff, 2008; Kinzel et al., 2007). The blue/ green wavelengths used in ALB typically have a $2 \mathrm{~m}$ footprint size (Guenther et al., 2000). However, Hilldale and Raff (2008) noticed that the problem with such large beam diameter is that the high relief features in the river bottom may produce errors, because the green pulse is reflected from the shallowest depth within the $2 \mathrm{~m}$ wide laser spot. Kinzel et al. (2007) used the Experimental Advanced Airborne Research LiDAR (EAARL), whose power is only $1 / 50$ th of other bathymetric lasers and, therefore, its beam diameter is only $0.15 \mathrm{~m}$, allowing a better spatial resolution. Conversely, this makes it less suitable for mapping bathymetry in depths greater than $10 \mathrm{~m}$, which, however, are not as 
common in river environments as in marine areas (Hilldale and Raff, 2008).

On the other hand, the use of ALB for mapping very shallow river areas is also problematic, because differentiation between the signals reflected from near the surface, turbidity and the riverbed is difficult (Kinzel et al., 2007). High turbidity, i.e. the reduced ability of light to penetrate water due to a high level of suspended particles, is a significant problem in sandybottomed rivers. Returns from turbidity and water surface may distort the elevations derived from the produced waveforms when terrestrial algorithms are used. According to a review by Feurer et al. (2008), the ALB is not generally suitable for mapping depths less than $0.50 \mathrm{~m}$. Bailly et al. (2010) suggested that depths less than the limit determined by the error standard deviation should not be mapped. For shallow water depth measurements, Kinzel et al. (2007) developed a bathymetric algorithm to differentiate the bottom returns from those of either turbidity or the water surface. This algorithm uses predefined acceptable pulse heights and widths for bottom return pulses. It also takes into account the different travel times of laser pulses in air and water. Allouis et al. (2010) also represented two methods for waveform processing, which can be used to determine the water depths. In their study, the method using green and near-infrared signals gave better results in river conditions than one which used Raman signals, i.e. red wavelength signals, which are produced when part of the energy of green laser is backscattered with a changed wavelength during the interaction with water molecules (Guenther et al., 1994). This was due to the sensitivity of the Raman signals to factors such as water constitution, turbidity and temperature, which can vary over short distances in river environments (Allouis et al., 2010; Fonstand and Marcus, 2005).

Water clarity affects the reflection and scatter of green laser pulses and is, therefore, an important factor affecting the maximum penetration depth of laser pulses (Guenther et al., 2000). In waters dominated by absorption or scattering, the depth measurement capability corresponds roughly to two and three Secchi depths, respectively. The Secchi depth refers to the depth of the disappearance of the Secchi disk, which describes the transparency of water and is dependent on water colour and turbidity (WMO, 1994). Some signals also penetrate deeper into the water, but the lower density of the returned signals from these depths may distort the bathymetric measurements (Bailly et al., 2010).

Despite the problems the ALB has in mapping of shallow water areas, it nevertheless has some distinct advantages over other methods used for mapping the bathymetry of deep river areas. For example, the mapping of greater depths is possible compared to optical imagery data, additional time-consuming ground surveys are not necessarily required, and the changes in substrate material, surface disturbance by waves and illumination conditions do not cause problems with ALB (Hilldale and Raff, 2008). On the other hand, just as with the optical imagery data, the ALB data can be affected by overhanging riparian or heavy aquatic vegetation, which may produce spurious data. In addition, significant air entrainment in the water column, for example in rapids, may affect the data. Compared to the total station or Kinematic GPS, ALB is a safer method in deep water areas with rapid discharges and is also more practical when long reaches are being mapped (Hilldale and Raff, 2008). Compared to the use of single beam SONAR or ADCP in conjunction with RTK-GPS, which is a common method used in bathymetric measurements, ALB requires less post-processing time. In addition, the greater point density of ALB data compared to traditional ground survey methods decreases the need for interpolation, thereby improving the accuracy of the surface model. Nevertheless, the precision of the ALB data is not as good as that of the traditional ground survey and much technical development is still required. Until then, 
other methods, such as passive optical imagery, can be used to complement the topographical LiDAR data (Aggett and Wilson, 2009; Gao, 2009; Legleiter et al., 2009).

\section{Assessment of fluvial processes and river dynamics}

The geomorphology and topography of the river channel and surrounding floodplain are affected by the fluvial erosion and deposition processes varying from a constant grain-scale displacement to large-scale flood-related avulsions (Aggett and Wilson, 2009; Milan et al., 2007). Two factors related to the capacity of a stream flow to transport sediment and to accomplish geomorphological work - i.e. shear stress (Wilkinson et al., 2004) and stream power (Knighton and Nanson, 1993; Magilligan, 1992; Miller, 1990; Nanson and Hickin, 1986; Rhoads, 1987) - are highly dependent on the riverbed roughness (Nelson et al., 2006) and slope gradient (Knighton, 1999; Lecce, 1997). Therefore, the definition of these two factors requires an accurate description of the channel and floodplain topography. High-resolution LiDAR data have distinct advantages in estimating roughness values, thus providing the potential also to improve shear stress and stream power estimates. Aggett and Wilson (2009) and Nelson et al. (2006) produced maps describing the spatial variation of boundary shear stress and unit stream power during flood events on the basis of LiDAR data. Aggett and Wilson (2009) also noticed that the estimation of the spatial variation of the shear stress computed from LiDAR DTM was more reliable than the one computed from a coarser USGS $30 \mathrm{~m}$ digital terrain model.

Furthermore, the use of LiDAR data has advantages in the estimation of erosion and deposition processes, particularly when long reaches are being studied (Hetherington et al., 2005; Lane et al., 2003; Rhoades et al., 2009; Thoma et al., 2005). A laser scanning survey is a substantially faster method and provides data from a more extensive area than either erosion pins (Lawler, 1993) or a total station survey (Thoma et al., 2005). For example, Rhoades et al. (2009) quantified the volumetric erosion rates of the riverbanks along a $40 \mathrm{~km}$ long reach using a combination of aerial imagery and riverbank elevation data derived from airborne LiDAR measurements. The volumetric measurements of sediment inputs would not have been possible without the integration of elevation data, because the aerial imagery allows only the detection of changes in two dimensions. The LiDAR data also allowed the authors to take better into consideration the spatial variation of the riverbank elevations.

LiDAR data have also been used for the estimation of the river sediment budget by subtracting the volume of deposition from the volume of erosion (Notebaert et al., 2009; Wheaton et al., 2009). For the identification of the sites of erosion and deposition, a comparison between detailed sequential topographical data of the river channel and surrounding floodplain is required. The ALS DTMs are suitable for the detection of large-scale changes in channel width and can be used in comparison with older topographical data. Conversely, subtraction between high-resolution sequential TLS DTMs from the same site allows the more accurate detection of very small changes over short time periods (Milan et al., 2007; Morche et al., 2008). A comparison of sequential LiDAR DTMs can also be used in landslide detection along the riverbanks, which can be identified from positive differences between the closest points of the newer laser point data set relative to the initial state at the toe of the slope and to negative differences at the head (Jaboyedoff et al., 2009). Jaboyedoff et al. (2009) showed that TLS data are particularly useful in quick surveys after landslides. The acquisition of TLS data can be undertaken immediately after the landslide and takes only a few hours, while a similar amount of time is required for data analysis. TLS data can be used for delineating the 
landslide area, determining its volume and creating profiles across the post-landslide slope. These profiles can be used, for example, to calculate the volume of material that has to be excavated to stabilize the slope. TLS data also allow better detection of small-scale changes of the riverbank morphology, such as ploughed furrows (i.e. small rivers and ponds that are caused by the slower weathering and erosion processes). TLS point data can also be used to model the geometry of the sliding surface and to examine the failure mechanism. Information provided by TLS data on small displacements prior to failure can also be useful in landslide detection and failure prediction.

Erosion and deposition calculations of the point bar based on very precise multitemporal BoMMS/CartMMS laser scanning can be undertaken with better spatial coverage and higher level of details compared to conventional EDM surveys (Alho et al., 2011). Laser scanned data provide dense data over large areas and allow continuous sampling and detection of fluvial geomorphology with a high level of detail. However, accuracy of the BoMMS LiDAR is not yet able to survey the smallest geomorphological features on the point bar (e.g. centimetre-scale ripples). CartMMS or TLS scanning is needed for these surveys.

However, some issues are associated with the detection of changes from DTMs. First, especially over longer temporal scales, accurate aerial imagery or LiDAR data are not normally available, and instead lower-quality historical topographical surveys need to be used in comparison (Notebaert et al., 2009). The present situation will improve as the current accuracy of LiDAR DTMs varies from a few millimetres (DTMs based on TLS) to less than $80 \mathrm{~cm}$ (DTMs derived from ALS) (Table 1) and these can be compared with even more accurate topographical maps of the future. The second issue is related to the propagation of error from DTMs to the surface of difference. Lane et al. (2003) showed that in low relief surfaces, in particular, the error propagation is significant and should be taken into account. Wheaton et al. (2009) introduced new methods for the analysis of uncertainty in elevation models that could also be utilized for the improvement of the sediment budget analysis based on LiDAR derived topographical data. Third, the detected volumes of erosion and deposition are dependent on the frequency of the laser scanning survey. Milan et al. (2007) noticed that the increased scanning frequency also increased the calculated volumes, which suggests that a higher (e.g. daily) scanning frequency is more likely to capture erosion and deposition episodes occurring within the studied river reach than a survey with several days' interval. This may lead to underestimations of the volume calculations. On the other hand, the scanning should not be conducted too frequently, because the occurred change may be so small that it is lost in the system noise (Thoma et al., 2005). This is especially true with ALS, in which both the vertical and horizontal errors are larger than those of TLS. Milan et al. (2007) suggested that surveys should be conducted after every flow that is capable of mobilizing the sediment material, which links the survey frequency to the activity of the studied river reach.

\section{River habitat modelling}

Topographical data from laser scanning surveys have also been increasingly applied for river habitat classification and modelling. For example, Andrew and Ustin (2009) used such data to predict the distribution of perennial pepperweed (Lepidium latifolium) in a river delta. Similarly, Kinzel et al. (2009) utilized ALS data to study the effect of the change of sandbar morphology and channel water level on the roosting habitat of the sand hill crane (Grus canadensis). Wilkins and Snyder (2010) derived a channel's width, gradient, shear stress and median grain size from ALS LiDAR data in order to estimate the effect of sediment grain size and its mobility in salmon habitats. 
Information from the water surface can be also utilized in habitat modelling. Although water surfaces, which are clear and still, do not usually reflect laser signals very well, surface disturbances caused by bottom roughness increases the possibility of reflectance. This allows the estimation of water surface roughness based on LiDAR data, which can be used in stream habitat classification (Large and Heritage, 2007; Milan et al., 2010). Compared to the high-intensity pulses reflected from exposed riverbed material or from the riverbanks, those reflected from the water surface are low in intensity, making it easy to distinguish between them (Milan et al., 2010).

Research on the application of TLS data on habitat modelling has shown some advantages over the traditional survey methods. Large and Heritage (2007) observed that one particular advantage of the use of the TLS data in habitat studies is that they allow a better quantification of biotope edges compared to traditional methods based on visual estimation utilized in the UK (Newson and Newson, 2000) or the rapid habitat survey methods used in mainland Europe (EAMN, 2004). The biotope edges are depicted as 'critical channel components' as they are important areas for a range of faunal activities, such as oviposition, feeding and hiding. Based on a LiDAR survey, Milan et al. (2010) also suggested that the biotope classification used for the biotope modelling by the European Aquatic Network (EAMN, 2004) should be simplified, because many biotopes show a considerable overlap in their spatial and temporal limits. The amalgamation of biotope types would also provide a more habitat-relevant approach for the biotope modelling.

\section{Conclusion}

This review of the application of laser scanning in fluvial studies has shown that LiDAR data have great potential to improve the effectiveness of topographical data acquisition and the accuracy and resolution of DTMs. Different laser scanning approaches also serve numerous research purposes. ALS is applicable for mapping areas varying from reach to catchment scale and these data are therefore particularly suitable, especially for hydraulic modelling, mapping of flood inundation, and the detection of macro-scale fluvial geomorphology. With TLS, a spatial resolution of less than $1 \mathrm{~mm}$ and a range accuracy of few millimetres can be achieved. MLS enables a remarkably faster survey approach compared to the conventional TLS method. The BoMMS scanning angle from the channel to the banks and point bars is also unique and, hence, it improves the spatial scanning coverage. The accuracy of the BoMMS/CartMMS laser scanning methods are noticeably better than ALS, mainly because of the closer viewpoint, higher angular resolution and, by definition, higher ranging accuracy.

Fluvial environments also offer challenges for the application of laser scanning techniques. Factors such as vegetation cover, terrain undulation, coarse surface materials and water surfaces may distort a LiDAR survey. Improved filtering techniques and different kinds of data combinations have proved useful for overcoming these challenges. For example, photography can be used to assist in the classification and densification of laser point clouds, while sonar data can be used to fill gaps produced by water bodies in LiDAR data. To date, bathymetric LiDAR has not been used much in the river environment and further development is still required, particularly in the mapping of shallow water areas and in increasing the footprint size of the laser beam. The development of LiDAR sensors with green light wavelengths in TLS or MLS would also improve the applicability of bathymetric LiDAR in fluvial studies.

\section{Acknowledgements}

This paper is the outcome of several years of fluvial and remote sensing studies in the authors' institutes. Financial support is offered by: VALUE Doctoral Program, TEKES (GIFLOOD research project); Academy 
of Finland (FINFLOODS, RivCHANGE and RoadSide research projects); Maj and Tor Nessling Foundation (FLOODAWARE research project); and Helsinki University of Technology (MIDE).

\section{References}

Aggett GR and Wilson JP (2009) Creating and coupling a high-resolution DTM with a 1-D hydraulic model in a GIS for scenario-based assessment of avulsion hazard in a gravel-bed river. Geomorphology 113: 21-34.

Ahokas E, Kaasalainen S, Hyyppä J, and Suomalainen J (2006) Calibration of the Optech ALTM 3100 laser scanner intensity data using brightness targets. International Archives of Photogrammetry and Remote Sensing, Marne-la-Vallee, France, 36 (A1), CD-ROM.

Alho P, Hyyppä H, and Hyyppä J (2009a) Consequence of DTM precision for flood hazard mapping: A case study in SW Finland. Nordic Journal of Surveying and Real Estate Research 6.

Alho P, Kukko A, Hyyppä H, Kaartinen H, Hyyppä J, and Jaakkola A (2009b) Application of boat-based laser scanning for river survey. Earth Surface Processes and Landforms 34: 1831-1838.

Alho P, Vaaja M, Kukko A, Kasvi E, Kurkela M, Hyyppä J, et al. (2011) Mobile laser scanning in fluvial geomorphology: Mapping and change detection of point bars. Zeitschrift für Geomorphologie 55 (Suppl. 2): 31-50.

Allouis T, Bailly JS, and Feurer D (2007) Assessing water surface effects on LiDAR bathymetry measurements in very shallow rivers: A theoretical study. Second ESA Space for Hydrology Workshop, Geneva, CHE, 1214 November 2007. Montpellier: CemOA Publications - Publications scientifiques et techniques du Cemagref.

Allouis T, Bailly J-S, Pastol Y, and Le Roux C (2010) Comparison of LiDAR waveform processing methods for very shallow water bathymetry using Raman, near-infrared and green signals. Earth Surface Processes and Landforms 35: 640-650.

Andrew ME and Ustin SL (2009) Habitat suitability modelling of an invasive plant with advanced remote sensing data. Diversity and Distributions 15: 627-640.

Axelsson P (2000) DEM generation from laser scanner data using adaptive TIN models. International Archives of Photogrammetry and Remote Sensing XXXIII (Part B4): 110-117.

Bailly JS, Le Coarer Y, Languille P, Stigermark CJ, and Allouis T (2010) Geostatistical estimations of bathymetric LiDAR errors on rivers. Earth Surface Processes and Landforms 35: 1199-1210.

Balletti C, Guerra F, Lingua A, and Rinaudo F (2003) True digital orthophoto of the San Marco Basilica in Venice. International Archives of the Photogrammetry, Remote Sensing and Spatial Information Sciences XXXIV (5/W12): 43-48.

Baltsavias E (1999a) A comparison between photogrammetry and laser scanning. ISPRS Journal of Photogrammetry and Remote Sensing 54: 83-94.

Baltsavias E (1999b) Airborne laser scanning: Basic relations and formulas. ISPRS Journal of Photogrammetry and Remote Sensing 54: 199-214.

Bates PD, Marks KJ, and Horritt MS (2003) Optimal use of high resolution topographic data in flood inundation models. Hydrological Processes 17: 537-557.

Bilker M and Kaartinen H (2001) The quality of Real-Time Kinematic (RTK) GPS positioning. Kirkkonummi: Reports of the Finnish Geodetic Institute 2001:1, 25 pp.

Bissonnette LR, Kunz G, and Weiss Wrana K (1997) Comparison of LiDAR and transmissometer measurements. Optical Engineering 36: 131-138.

Brenner C (2005) Building reconstruction from images and laser scanning. International Journal of Applied Earth Observation and Geoinformation 6: 187-198.

Bufton JL (1989) Laser altimetry measurements from aircraft and spacecraft. Proceedings of the IEEE 77: 463-477.

Burton SP, Ferrare RA, Hostetler CA, Hair JW, Kittaka C, Vaughan MA, et al. (2010) Using airborne high spectral resolution lidar data to evaluate combined active plus passive retrievals of aerosol extinction profiles. Journal of Geophysical Research 115: D00H15.

Butler JB, Lane SN, and Chandler JH (1998) Assessment of DEM characterizing surface roughness using close range digital photogrammetry. Photogrammetric Record 16: 271-291.

Candela T, Renard F, Bouchon M, Brouste A, Marsan D, Schmittbuhl J, et al. (2009) Characterization of fault roughness at various scales: Implications of threedimensional high resolution topography measurements. Pure and Applied Geophysics 166: 1817-1851.

Carey CJ, Brown TG, Challis KC, Howard AJ, and Cooper L (2006) Predictive modelling of multiperiod geoarchaeological resources at a river confluence: A case study from the Trent-Soar, UK. Archaeological Prospection 13: 241-250.

Cavalli M, Tarolli P, Marchi L, and Fontana GD (2008) The effectiveness of airborne LiDAR data in the 
recognition of channel-bed morphology. Catena 73: 249-260.

Charlton ME, Large ARG, and Fuller IC (2003) Application of airborne LiDAR in river environments: The river Coquet, Northhumberland, UK. Earth Surface Processes and Landforms 28: 299-306.

Cobby DM, Mason DC, and Davenport IJ (2001) Image processing of airborne scanning laser altimetry data for improved river flood modelling. Photogrammetry and Remote Sensing 56: 121-138.

Cobby DM, Mason DC, Horritt MS, and Bates PD (2003) Two dimensional hydraulic flood modelling using a finite-element mesh decomposed according to vegetation and topographic features derived from airborne scanning laser altimetry. Hydrological Processes 17: 1979-2000.

Cook A and Merwade V (2009) Effect of topographic data, geometric configuration and modeling approach on flood inundation mapping. Journal of Hydrology 377: 131-142.

Coren F and Sterzai P (2006) Radiometric correction in laser scanning. International Journal of Remote Sensing 27: 3097-3104.

Davenport IJ, Bradbury RB, Anderson GRF, Hayman JR, Krebs JR, Mason DC, et al. (2000) Improving bird population models using airborne remote sensing. International Journal of Remote Sensing 21: 2705-2717.

Doneus M, Briese C, and Studnicka N (2010) Analysis of full-waveform ALS data by simultaneously acquired TLS data. Towards an advanced DTM generation in wooded areas. ISPRS Commission VII Symposium, 5-7 July 2010, Vienna.

Entwistle NS and Fuller IC (2009) Terrestrial laser scanning to derive the surface grain size facies character of gravel bars. In: Heritage GL and Large ARG (eds) Laser Scanning for the Environmental Sciences, Chichester: Wiley, 102-114.

European Aquatic Monitoring Network (EAMN) (2004) State-of-the-art in data sampling, modelling analysis and applications of river habitat modelling (edited by Harby A, Baptist M, Michael J, Dunbar MJ, and Schmutz S). COST Action Report 626.

Feurer D, Bailly J-S, Puech C, Le Coarer Y, and Viau AA (2008) Very-high-resolution mapping of riverimmersed topography by remote sensing. Progress in Physical Geography 32: 403-419.

Flood M and Gutelius B (1997) Commercial implication of topographic terrain mapping using scanning airborne laser radar. ISPRS Journal of Photogrammetry and Remote Sensing 66: 327-329.

Fonstand MA and Marcus WA (2005) Remote sensing of stream depths with hydraulically assisted bathymetry (HAB) models. Geomorphology 72: 320-339.

Frankel KL and Dolan JF (2007) Characterizing arid region alluvial fan surface roughness with airborne laser swath mapping digital topographic data. Journal of Geophysical Research 112: F02025.

French JR (2003) Airborne LiDAR in support of geomorphological and hydraulic modelling. Earth Surface Processes and Landforms 28: 321-335.

Gao J (2009) Bathymetric mapping by means of remote sensing: Methods, accuracy and limitations. Progress in Physical Geography 33: 103-116.

Guenther GC (2007) Airborne lidar bathymetry. In: Maune DF (ed.) Digital Elevation Model Technologies and Applications: The DEM User's Manual, second edition. Bethesda, MD: American Society for Photogrammetry and Remote Sensing, 253-320.

Guenther GC, Cunningham AG, LaRocque PE, and Ried DJ (2000) Meeting the accuracy challenge in airborne LiDAR bathymetry. In: Proceedings of EARSeL-SIG Workshop LiDAR No. 1, Dresden, 16-17 June.

Guenther G, LaRocque P, and Lillycrop W (1994) Multiple surface channels in SHOALS airborne LiDAR. SPIE: Ocean Optics XII 2258: 422-430.

Gueudet P, Wells G, Maidment DR, and Neuenschwander A (2004) Influence of the postspacing density of the LiDARderived DEM on flood modeling. Geographic Information Systems and Water Resources III - AWRA Spring Specialty Conference. AWRA, Nashville, Tennessee.

Harding DJ and Berghoff GS (2000) Fault scarp detection beneath dense vegetation cover: Airborne LIDAR mapping of the Seattle Fault Zone, Bainbridge Island, Washington State. Proceedings of the American Society of Photogrammetry and Remote Sensing Annual Conference, Washington, DC.

Hayakawa Y and Oguchi T (2005) Evaluation of gravel sphericity and roundness based on surface-area measurement with a laser scanner. Computers and Geosciences 31: 735-741.

Heritage G and Hetherington D (2007) Towards a protocol for laser scanning in fluvial geomorphology. Earth Surface Processes and Landforms 32: 66-74.

Heritage GL and Milan DJ (2009) Terrestrial laser scanning of grain roughness in a gravel-bed river. Geomorphology 113: 4-11. 
Hetherington D, Heritage G, Milan D, Walling DE, and Horowitz AJ (2005) Daily fine sediment dynamics on an active Alpine glacier outwash plain. Sediment Budgets, International Symposium on Sediment Budgets held at the 7th Scientific Assembly of the International Association of Hydrological Sciences 291: 278-284.

Hickman GD and Hogg JE (1969) Application of an airborne pulsed laser for near shore bathymetric measurements. Remote Sensing of Environment 1: 47-58.

Hilldale RC and Raff D (2008) Assessing the ability of airborne LiDAR to map river bathymetry. Earth Surface Processes and Landforms 33: 773-783.

Hodge R, Brasington J, and Richards K (2009a): Analysing laser-scanned digital terrain models of gravel bed surfaces: Linking morphology to sediment transport processes and hydraulics. Sedimentology 56: 2024-2043.

Hodge R, Brasington J, and Richards K (2009b) In situ characterization of grain-scale fluvial morphology using Terrestrial Laser Scanning. Earth Surface Processes and Landforms 34: 954-968.

Hodgson E and Bresnahan P (2004) Accuracy of airborne lidar-derived elevation: Empirical assessment and error budget. Photogrammetric Engineering and Remote Sensing 70: 331-339.

Hodgson ME, Jensen JR, Schmidt L, Schill S, and Davis B (2003) An evaluation of lidar- and IFSAR-derived digital elevation models in leaf-on conditions with USGS Level 1 and Level 2 DEMs. Remote Sensing of Environment 84: 295-308.

Höfle B and Pfeifer N (2007) Correction of laser scanning intensity data: Data and model-driven approaches. ISPRS Journal of Photogrammetry and Remote Sensing 62: 415-433.

Hollaus M, Wagner W, and Kraus K (2005) Airborne laser scanning and usefulness for hydrological models. Advances in Geosciences 5: 57-63.

Hopkinson C, Chasmer L, Munro S, and Demuth MN (2010) The influence of DEM resolution on simulated solar radiation-induced glacier melt. Hydrological Processes 24: 775-788.

Huising EJ and Gomes Pereira LM (1998) Errors and accuracy of laser data acquired by various laser scanning systems for topographic applications. ISPRS Journal of Photogrammetry and Remote Sensing 53: 245-261.

Hyyppä H, Yu X, Hyyppä J, Kaartinen H, Honkavaara E, and Rönnholm P (2005) Factors affecting the quality of DTM generation in forested areas. In: Proceedings of ISPRS Workshop Laser Scanning 2005, 12-14 September, Enschede, Netherlands, (Netherlands: GITCbv), XXXVI (Part 3/W19), 85-90.

Hyyppä J, Hyyppä H, Leckie D, Gougeon F, Yu X, and Maltamo M (2008) Review of methods of smallfootprint airborne laser scanning for extracting forest inventory data in boreal forests. International Journal of Remote Sensing 29: 1339-1366.

Hyyppä J, Schardt M, Haggrén H, Koch B, Lohr U, Scherrer HU, et al. (2001) HIGH-SCAN: The first European-wide attempt to derive single-tree information from laser scanner data. The Photogrammetric Journal of Finland 17: 58-68.

Ibbeken H and Schleyer R (1986) Photo-sieving: A method for grain-size analysis of coarsegrained, unconsolidated bedding surfaces. Earth Surface Processes and Landforms 11: 59-77.

Irish JL and Lillycrop WJ (1999) Scanning laser mapping of the coastal zone: The SHOALS system. ISPRS Journal of Photogrammetry and Remote Sensing 54: 123-129.

Irish JL and White TE (1998) Coastal engineering applications of high-resolution LiDAR bathymetry. Coastal Engineering 35: 47-71.

Jaakkola A, Hyyppä J, Hyyppä H, and Kukko A (2008) Retrieval algorithms for road surface modelling using laser-based mobile mapping. Sensors 8: 5238-5249.

Jaboyedoff M, Demers D, Locat J, Locat A, Locat P, Oppikofer T, et al. (2009) Use of terrestrial laser scanning for the characterization of retrogressive landslides in sensitive clay and rotational landslides in river banks. Canadian Geotechnical Journal 46: 1379-1390.

Jackson TJ, Ritchie JC, White J, and Leschack L (1988) Airborne laser profile data for measuring ephemeral gully erosion. Photogrammetric Engineering and Remote Sensing 54: 1181-1185.

Jones A, Brewer PA, Johnstone E, and Macklin MG (2007) High-resolution interpretative geomorphological mapping of river valley environments using airborne LiDAR data. Earth Surface Processes and Landforms 32: 1574-1592.

Jones KL, Poole GC, O'Daniel SJ, Mertes LAK, and Stanford JA (2008) Surface hydrology of low-relief landscapes: Assessing surface water flow impedance using LIDAR-derived digital elevation models. Remote Sensing of Environment 112: 4148-4158.

Kaartinen H and Hyyppä J (2006) Evaluation of building extraction. EuroSDR - European Spatial Data Research, Official Publication 50: 9-77. 
Kaartinen H, Hyyppä J, and Kukko M (forthcoming) On the accuracy of mobile laser scanning. Remote Sensing Open Access Journal.

Kaasalainen S, Hyyppä H, Kukko A, Litkey P, Ahokas E, Hyyppä J, et al. (2009) Radiometric calibration of LIDAR intensity with commercially available reference targets. IEEE Transactions on Geoscience and Remote Sensing 47: 588-598.

Kinzel PJ, Nelson JM, and Heckman AK (2009) Response of sandhill crane (Grus canadensis) riverine roosting habitat to changes in stage and sandbar morphology. River Research and Applications 25: 135-152.

Kinzel PJ, Wright CW, Nelson JM, and Burman AR (2007) Evaluation of an experimental LiDAR for surveying a shallow, braided, sand-bedded river. Journal of Hydraulic Engineering 133: 838-842.

Knighton AD (1999) Downstream variation in stream power. Geomorphology 29: 293-306.

Knighton AD and Nanson GC (1993) Anastomosis and the continuum of channel pattern. Earth Surface Processes and Landforms 18: 613-625.

Kobler A, Pfeifer N, Ogrinc P, Todorovski L, Ostir K, and Dzeroski S (2007) Repetitive interpolation: A robust algorithm for DTM generation from Aerial Laser Scanner Data in forested terrain. Remote Sensing of Environment 108: 9-23.

Krabill WB, Collins JG, Link LE, Swift RR, and Butler ML (1984) Airborne laser topographic mapping results. Photogrammetric Engineering and Remote Sensing 50: 685-94.

Krabill W, Frederick E, Manizade S, Martin C, Sonntag J, Swift R, et al. (1999) Rapid thinning of parts of the southern Greenland ice sheet. Science 283: 1522-1524.

Kraus K and Otepka J (2005) DTM modelling and visualization - the SCOP approach. In: Photogrammetric Week. Heidelberg: Wichmann Verlag, 241-252.

Kraus K and Pfeifer N (1998) Determination of terrain models in wooded areas with airborne laser scanner data. ISPRS Journal of Photogrammetry and Remote Sensing 53: 193-203.

Kukko A, Andrei C-O, Salminen V-M, Kaartinen H, Chen Y, Rönnholm P, et al. (2007) Road environment mapping system of the Finnish Geodetic Institute - FGI Roamer. In: Rönnholm P, Hyyppä H, and Hyyppä J (eds) Proceedings of the ISPRS Workshop 'Laser Scanning 2007 and SilviLaser 2007', Espoo, Finland, 12-14 September, 241-247.

Lane SN, Chandler JH, and Richards KS (1998) Landform monitoring, modelling and analysis: Landform in geomorphological research. In: Lane SN, Richards KS, and Chandler JH (eds) Landform Monitoring, Modelling and Analysis. Chichester: Wiley, 1-18.

Lane S, Westaway RM, and Hicks DM (2003) Estimation of erosion and deposition volumes in a large, gravelbed, braided river using synoptic remote sensing. Earth Surface Processes and Landforms 28: 249-271.

Large A and Heritage G (2007) Terrestrial laser scanner based instream habitat quantification using a random field approach. In: Proceedings of the 2007 Annual Conference of the Remote Sensing and Photogrammetry Society (RSPSoc2007), Newcastle Upon Tyne, 11-14 September, TS3.

Large A and Heritage GL (2009) Laser scanning - evolution of the discipline. In: Heritage GL and Large ARG (eds) Laser Scanning for the Environmental Sciences. Chichester: Wiley, 1-20.

Lawler DM (1993) The measurement of river bank erosion and lateral channel change: A review. Earth Surface Processes and Landforms 18: 777-821.

Lawrence JP, Leigh RJ, and Monks PS (2010) The impact of surface reflectance variability on total column differential absorption LiDAR measurements of atmospheric $\mathrm{CO}_{2}$. Atmospheric Measurement Techniques Discussions 3: 147-184.

Lecce SA (1997) Nonlinear downstream changes in stream power on Wisconsin's Blue River. Annals of the Association of American Geographers 87: 471-486.

Legleiter CJ, Roberts DA, and Lawrence RL (2009) Spectrally based remote sensing of river bathymetry. Earth Surface Processes and Landforms 34: 1039-1059.

Lim K, Treitz P, Wulder M, St-Onge B, and Flood M (2003) LiDAR remote sensing of forest structure. Progress in Physical Geography 27: 88-106.

Lohr U and Eibert M (1995) The TopoSys Laser ScannerSystem. In: Fritsch D and Hobbie D (eds) Photogrammetric Week'95. Heidelberg: Wichmann.

Maas H-G and Vosselman G (1999) Two algorithms for extracting building models from raw laser altimetry data. Photogrammetry and Remote Sensing 54: 153-163.

Magilligan FJ (1992) Thresholds and the spatial variability of flood power during extreme floods. Geomorphology 5: 373-390.

Maiman TH (1960) Stimulated optical radiation in ruby. Nature 187: 493-494.

Mandlburger G, Hauer C, Höfle B, Habersack H and Pfeifer N (2009) Optimization of LiDAR derived terrain 
models for river flow modelling. Hydrology and Earth System Sciences 13: 1453-1466.

Marcus WA and Fonstand MA (2008) Optical remote mapping of rivers at sub-meter resolutions and watershed extents. Earth Surface Processes and Landforms 33: 4-24.

Marks K and Bates P (2000) Integration of high-resolution topographic data with floodplain flow models. Hydrological Processes 14: 2109-2122.

Mason DC, Cobby DM, Horritt MS, and Bates PD (2003) Floodplain friction parameterization in twodimensional river flood models using vegetation heights derived from airborne scanning laser altimetry. Hydrological Processes 17: 1711-1732.

Mason DC, Horritt MS, Dall'Amico JT, Scott TR, and Bates PD (2007) Improving river flood extent delineation from synthetic aperture radar using airborne laser altimetry. IEEE Transactions on Geoscience and Remote Sensing 45: 3932-3943.

Mason DC, Scott TR, and Wang HJ (2006) Extraction of tidal channel networks from airborne scanning laser altimetry. ISPRS Journal of Photogrammetry and Remote Sensing 61: 67-83.

Milan DJ (2009) Terrestrial laser scan-derived topographic and roughness data for hydraulic modelling of gravelbed rivers. In: Heritage GL and Large ARG (eds) Laser Scanning for the Environmental Sciences. Chichester: Wiley, 133-146.

Milan DJ, Heritage GL, and Hetherington D (2007) Application of a 3D laser scanner in the assessment of erosion and deposition volumes and channel change in a proglacial river. Earth Surface Processes and Landforms 32: 1657-1674.

Milan DJ, Heritage GL, Large ARG, and Entwistle NS (2010) Mapping hydraulic biotopes using terrestrial laser scan data of water surface properties. Earth Surface Processes and Landforms 35: 918-931.

Millane RP, Fitzsimons ME, Qi M, and Haider A (2006a) Analysis of gravel river beds using three-dimensional laser scanning. Image Reconstruction from Incomplete Data IV: 63160B.

Millane RP, Weir MI, and Smart GM (2006b) Automated analysis of imbrication and flow direction in alluvial sediments using laser-scan data. Journal of Sedimentary Research 76: 1049-1055.

Miller AJ (1990) Flood hydrology and geomorphic effectiveness in the central Appalachians. Earth Surface Processes and Landforms 15: 119-134.
Morche D, Schmidt KH, Sahling I, Herkommer M, and Kutschera J (2008) Volume changes of Alpine sediment stores in a state of post-event disequilibrium and the implications for downstream hydrology and bed load transport. Norsk Geografisk Tidsskrift Norwegian Journal of Geography 62: 89-101.

Nanson GC and Hickin EJ (1986) A statistical examination of bank erosion and channel migration in western Canada. Bulletin of the Geological Society of America 97: 497-504.

Nelson PA, Smith JA, and Miller AJ (2006) Evolution of channel morphology and hydrologic response in an urbanizing drainage basin. Earth Surface Processes and Landforms 31: 1063-1079.

Nelson R, Krabill W, and Maclean G (1984) Determining forest canopy characteristics using airborne lidar data. Remote Sensing of Environment 15: 201-212.

Newson MD and Newson CL (2000) Geomorphology, ecology and river channel habitat: Mesoscale approaches to basin-scale challenges. Progress in Physical Geography 24: 195-217.

Notebaert B, Verstraeten G, Govers G, and Poesen J (2009) Qualitative and quantitative applications of LiDAR imagery in fluvial geomorphology. Earth Surface Processes and Landforms 34: 217-231.

Omer CR, Nelson J, and Zundel AK (2003) Impact of varied data resolution on hydraulic modeling and floodplain delineation. Journal of the American Water Resources Association 39: 467-475.

Oude Elberink S and Maas H-G (2000) The use of anisotropic height texture measures for the segmentation of airborne laser scanner data. International Archives of Photogrammetry and Remote Sensing 33: 678-684.

Overton IC, Siggins A, Gallant JC, Penton D, and Byrne G (2009) Flood modelling and vegetation mapping in large river systems. In: Heritage GL and Large ARG (eds) Laser Scanning for the Environmental Sciences. Chichester: Wiley, 220-244.

Packman AI and Brooks NH (2001) Hyporheic exchange of solutes and colloids with moving bed forms. Water Resources Research 37: 2591-2605.

Packman AI, Brooks NH, and Morgan JJ (1997) Experimental techniques for laboratory investigation of clay colloid transport and filtration in a stream with a sand bed. Water, Air, and Soil Pollution 99: 113-122.

Parson LE, Lillycrop WJ, Klein CJ, Ives RCP, and Orlando SP (1997) Use of LiDAR technology for collecting 
shallow water bathymetry of Florida Bay. Journal of Coastal Research 13: 1173-1180.

Pereira LMG and Wicherson RJ (1999) Suitability of laser data for deriving geographical information: A case study in the context of management of fluvial zones. ISPRS Journal of Photogrammetry and Remote Sensing 54: 105-114.

Perroy RL, Bookhagen B, Asner G, and Chadwick OA (2010) Comparison of gully erosion estimates using airborne and ground-based LiDAR on Santa Cruz Island, California. Geomorphology 118: 288-300.

Price WF and Uren J (1989) Laser Surveying. London: Van Nostrand Reinhold (International).

Reutebuch S, McGaughey R, Andersen H, and Carson W (2003) Accuracy of a high-resolution lidar terrain model under a conifer forest canopy. Canadian Journal of Remote Sensing 22: 527-535.

Rhoads BL (1987) Stream power terminology. Professional Geographer 39: 189-195.

Rhoades EL, O'Neal MA, and Pizzuto JE (2009) Quantifying bank erosion on the South River from 1937 to 2005, and its importance in assessing $\mathrm{Hg}$ contamination. Applied Geography 29: 125-134.

Ritchie JC and Jackson TJ (1989) Airborne laser measurements of the surface-topography of simulated concentrated flow gullies. Transactions of the ASAE 32: 645-648.

Rönnholm P, Hyyppä H, Pöntinen P, Haggrén H, and Hyyppä J (2003) A method for interactive orientation of digital images using backprojection of 3D data. The Photogrammetric Journal of Finland 18: 58-69.

Rumsby BT, Brasington J, Langham JA, Mclelland SJ, Middleton R, and Rollinson G (2008) Monitoring and modelling particle and reach-scale morphological change in gravel-bed rivers: Applications and challenges. Geomorphology 93: 40-54.

Sanders BF (2007) Evaluation of on-line DEMs for flood inundation modelling. Advances in Water Resources 30: $1831-1843$.

Schreier H, Lougheed J, Tucker C, and Leckie D (1985) Automated measurement of terrain reflection and height variations using an airborne infrared laser system. International Journal of Remote Sensing 6: 101-113.

Shan J and Toth CK (eds) (2009) Topographic Laser Ranging and Scanning. Boca Raton, FL: CRC Press, 590 pp.

Sithole G and Vosselman G (2004) Experimental comparison of filter algorithms for bare earth extraction from airborne laser scanning point clouds. ISPRS Journal of Photogrammetry and Remote Sensing 59: 85-101.

Smullins LD and Fiocco G (1962) Optical echoes from the Moon. Nature 194: 1267.

Solodukhin V, Zukov A, and Mazugin I (1977) Possibilities of laser aerial photography for forest profiling. Lesnoe Khozyaisto (Forest Management) 10: 53-58 (in Russian).

Straatsma MW (2008) Quantitative mapping of hydrodynamic vegetation density of floodplain forests under leaf-off conditions using airborne laser scanning. Photogrammetric Engineering and Remote Sensing 74: 987-998.

Straatsma MW and Baptist M (2008) Floodplain roughness parameterization using airborne laser scanning and spectral remote sensing. Remote Sensing of Environment 112: 1062-1080.

Straatsma MW and Middelkoop H (2006) Airborne laser scanning as a tool for lowland floodplain vegetation monitoring. Hydrobiologia 565: 87-103.

Takeda H (2004) Ground surface estimation in dense forest. The International Archives of Photogrammetry, Remote Sensing and Spatial Information Sciences 35 (part B3): 1016-1023.

Thoma DP, Gupta SC, Bauer ME, and Kirchoff CE (2005) Airborne laser scanning for riverbank erosion assessment. Remote Sensing of Environment 95: 493-501.

Tsubaki R and Fujita I (2010) Unstructured grid generation using LiDAR data for urban flood inundation modelling. Hydrological Processes 24: 1404-1420.

Vosselman G and Maas H-G (2010) Airborne and Terrestrial Laser Scanning. Dunbeath: Whittles Publishing, $336 \mathrm{pp}$.

Wadhams P and Wallis M (1995) Arctic sea-ice extent and thickness. Philosophical Transactions of the Royal Society of London Series A 352: 301-319.

Wagner W (2010) Radiometric calibration of smallfootprint full-waveform airborne laser scanner measurements: Basic physical concepts. ISPRS Journal of Photogrammetry and Remote Sensing 65: 505-513.

Wagner W, Ullrich A, Ducic V, Melzer T, and Studnicka N (2006) Gaussian decomposition and calibration of a novel small-footprint full-waveform digitizing airborne laser scanner. ISPRS Journal of Photogrammetry and Remote Sensing 60: 100-112.

Wang C-K and Philpot WD (2007) Using airborne bathymetric lidar to detect bottom type variation in shallow waters. Remote Sensing of Environment 106: 123-135. 
Wang Y and Zheng T (2005) Comparison of light detection and ranging and National Elevation Dataset digital elevation model on floodplains of North Carolina. Natural Hazards Review 6: 34-40.

Wechsler N, Rockwell TK, and Ben-Zion Y (2009) Application of high resolution DEM data to detect rock damage from geomorphic signals along the central San Jacinto Fault. Geomorphology 113: 82-96.

Wever C and Lindenberger J (1999) Laserscanning - a mapping method gains ground. Photogrammetric Week 99: 125-132.

Wheaton JM, Brasington J, Darby SE, and Sear DA (2009) Accounting for uncertainty in DEMs from repeat topographic surveys: Improved sediment budgets. Earth Surface Processes and Landforms 35: 136-156.

Wilkins BC and Snyder NP (2010) Geomorphic comparison of two Atlantic coastal rivers: Toward an understanding of physical controls of Atlantic salmon habitat. River Research and Applications 27: 135-156.

Wilkinson SN, Keller RJ, and Rutherfurd ID (2004) Phaseshift in shear stress as an explanation for the maintenance of pool-riffle sequences. Earth Surface Processes and Landforms 29: 737-753.

Wolman MG (1954) A method of sampling coarse riverbed material. Transactions of the American Geophysical Union 35: 951-956.

World Meteorological Organization (WMO) (1994) Guide to Hydrological Practices: Data Acquisition and Processing, Analysis, Forecasting and Other Applications, fifth edition. Geneva: WMO-No. 168, 730 pp.

Zhao H and Shibasaki R (2003) A vehicle-borne urban 3-D acquisition system using single-row laser range scanners. IEEE Transactions on Systems, Man, and Cybernetics - Part B: Cybernetics 33: 658-666. 